\title{
Development of self-assembled poly(2-ethyl-2-oxazoline)-b-poly(e-caprolactone) (PEtOx-b-PCL) copolymeric nanostructures in aqueous solution and evaluation of their morphological transitions
}

\author{
U. U. Ozkose $e^{1,2,3}$, S. Gulyuz ${ }^{1,2}$, U. C. Oz ${ }^{4}$, M. A. Tasdelen ${ }^{5}$, O. Alpturk ${ }^{1}$, A. Bozkir ${ }^{4}$, O. Yilmaz ${ }^{2 *}$ \\ ${ }^{1}$ Department of Chemistry, Faculty of Science and Letters, Istanbul Technical University, Maslak, 34469 Istanbul, Turkey \\ ${ }^{2}$ Materials Institute, Marmara Research Center, TUBITAK, Gebze, 41470 Kocaeli, Turkey \\ ${ }^{3}$ Department of Chemistry, Faculty of Science and Letters, Piri Reis University, Tuzla, 34940 Istanbul, Turkey \\ ${ }^{4}$ Department of Pharmaceutical Technology, Faculty of Pharmacy, Ankara University, Yenimahalle, 06560 Ankara, Turkey \\ ${ }^{5}$ Department of Polymer Engineering, Faculty of Engineering, Yalova University, Yalova 77200, Turkey
}

Received 26 February 2020; accepted in revised form 26 April 2020

\begin{abstract}
Amphiphilic block copolymers are known to self-assemble into various morphologies, including ellipsoids, tubular structures, toroids, vesicles, micellar structures. In this paper, we discuss the synthesis of copolymeric nanostructures (CNs) using poly(2-ethyl-2-oxazoline)-block-poly( $\varepsilon$-caprolactone) (PEtOx- $b$-PCL) amphiphilic block copolymers. Our data indicate that - varying the molecular weight and the number of repeating units dictate the nature of morphology. That is, the formation of self-assembled morphologies from ellipsoid to rod-like architectures are observed in aqueous solution, depending on the mass ratio of the hydrophilic block $\left(f_{\mathrm{PEtOx}}\right)$. To best of our knowledge, this is the first report on the morphological transitions of PEtOx- $b$-PCL amphiphilic block copolymer-based CNs with different $f_{\mathrm{PEtOx}}$ values in the literature.
\end{abstract}

Keywords: nanomaterials, poly(2-ethyl-2-oxazoline), amphiphilic block copolymers, self-assembly, morphological transition

\section{Introduction}

Self-assembly of the block copolymers is an active and widescale field since it is one of the most important nanotechnological methods to prepare nanocarriers for different applications. The block copolymer self-assemblies have been intensively examined since the 1960s, and a vast number of data have been published about this topic [1-5]. On the other hand, the self-assembly of block copolymers in aqueous solutions has been actively studied, although the existence of various morphologies of block copolymers in aqueous solution has been known for many years [6-8]. Especially, small molecule amphiphilic surfactant systems that form self-assembled aggregates of multiple morphologies in aqueous solutions have been extensively studied for many decades and the precise nature of the various nanostructures formed in aqueous solution was influenced by the surfactant concentration [9-11].

In the wake of advances in polymer synthesis, a broad variety of amphiphilic block copolymer self-assemblies including ellipsoids [12], tubular structures [13], micellar structures [7, 14-18], toroids [19], vesicles (a.k.a., polymersomes) [7, 20-24], which ensure potential and practical applications in plenty of biomedical fields [25], has been achieved. The large emphasis on these nanostructures is founded on the observation of $\mathrm{CNs}$ that can respond to external 
stimuli, such as $\mathrm{pH}[26,27]$, oxidation [28], temperature [29] and that they offer researchers a tremendous platform to formulate drug delivery systems $[25,30]$. In the early stages concerning the self-assembly of amphiphilic diblock copolymers, such as poly(styrene)-block-poly(acrylic acid) (PS-b-PAA) or poly(styrene)-block-poly(ethylene oxide) (PS-bPEO), it was demonstrated that those with the hydrophilic blocks shorter than the hydrophobic blocks, yield a variety of morphologies with a larger hydrophobic region than the structure corona $[7,8,31-$ 33]. In contrast, self-assemblies (usually spherical micelles) in which the coronas are much larger than the core regions are often referred to as 'star-like' structures [32].

Concerning the synthesis of self-assembled CNs, there has been remarkable progress in controlling shapes (especially on the sub-100 nm scale). In that regard, the ultimate 'fate' of their morphology is contingent on a variety of physicochemical phenomena, such as spontaneous curvature, hydrophobic/hydrophilic balance of copolymer blocks (' $f_{\text {hydrophilic }}$ ' $=$ percent mass ratio of copolymer's hydrophilic fraction to total block copolymer), interfacial energy between copolymer blocks, packing parameter, and hydrophilic block's state of order, as well as the nature of the process (for instance, solvent exchange, film rehydration, $\mathrm{pH}$ switch and so on) [34]. Particularly, it is well-recognized that $f_{\text {hydrophilic }}$ value is what governs the formation of self-assemblies, followed by their dynamic morphological transition in solution. Nanostructures with different morphologies were obtained by using block copolymers where the $f_{\text {hydrophilic }}$ value is in the range of $0.2-0.3$, and these examples were described in the literature [35-40]. Naturally, this observation stems from the thermodynamics of the whole process, wherein hydrophobic fractions of block copolymer self-assemblies in an attempt to minimize their contact with water, while hydrophilic ones tend to locate on the surface of the membrane [41].

In that regard, the morphological transitions of block copolymers in aqueous media have been studied extensively for certain block copolymers, to date. Although these studies have mostly focused on non-biodegradable copolymers (e.g., PS-PAA [42], PGMAPHPMA [43], PEO-PDMS [44]), some biodegradable copolymers (PEG-PDLLA [45], ELP-PBLG [46]) have also been taken into account, as well. To this date, it is well-known that the morphological transition of these block CNs can be achieved by adjusting the nature of the repeating unit, molecular weight, and the relative block length [47]. Besides, it has been reported that copolymers having a molecular weight in the range of $2-20 \mathrm{kDa}$ can self-assemble into various nanoscopic structures [48]. To this end, we have previously reported the design of PEtOx based vesicles [49] and several research groups prepared PEtOx-harboring block copolymers in many forms, including scaffold [50], hydrogel [51], conjugate [52], micelle [53], liposome [54] for various applications. In that context, we reported the synthesis of PEtOx- $b$-PCL amphiphilic block copolymers, wherein PEtOx served as hydrophilic fragment [55, 56]. In doing this, we came to notice that the nature of CNs derived from these block copolymers and their morphological transitions are not investigated to date.

In this study, we report the synthesis of copolymeric nanostructures from PEtOx- $b$-PCL amphiphilic blocks and studied their morphological transitions. The CNs with different $f_{\text {PEtOx }}$ values were obtained via the solvent-switch method [57] using these copolymers, and the morphological transitions from ellipsoid to rod-like architectures were monitored with transmission electron microscopy (TEM), in keeping with relevant literature [41, 43]. After all, for the first time, the morphological transitions of PEtOx- $b$-PCL copolymers in aqueous solution were proved by adjusting the molecular weight and the number of repeating units. Overall, after further investigations, these strong findings suggest that PEtOx- $b$-PCL amphiphilic block copolymer-based CNs can be used as drug/biomacromolecule delivery

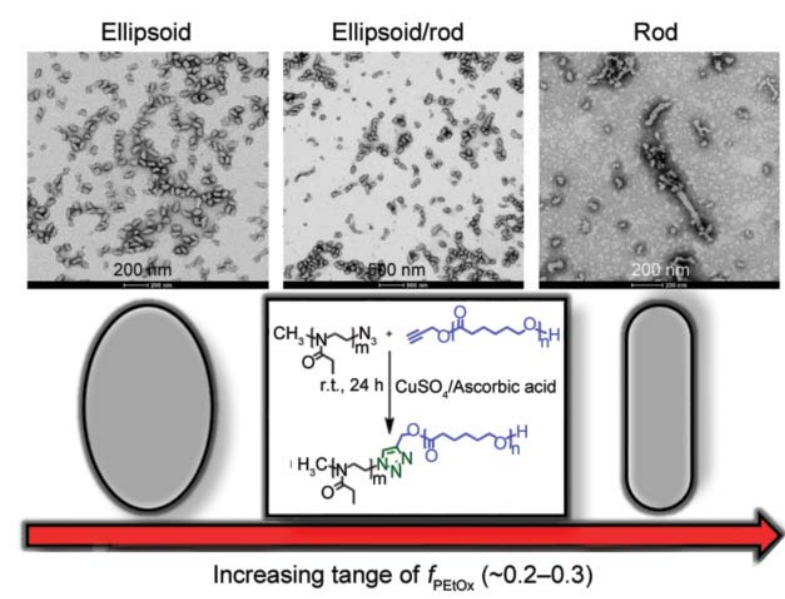

Figure 1. The morphological transitions of PEtOx- $b$-PCL $\mathrm{CNs}$ in aqueous solution upon altering the molecular weight, and the number of repeating units. 
and release tools, diagnostic imaging agents, and nanoreactors for diverse bioapplications [58]. The morphological transition is shown schematically in Figure 1.

\section{Experimental \\ 2.1. Materials}

2-Ethyl-2-oxazoline (EtOx, $\geq 99 \%, 137456$, Aldrich, Germany), and $\varepsilon$-caprolactone (CL, 99\%, 173442500, Acros, Japan) were dried over calcium hydride (95\%, 208027, Aldrich, Germany) overnight and purified by vacuum distillation. These monomers were stored under nitrogen atmosphere until use. Methyl $p$-toluenesulfonate (MeTos, $\geq 98 \%, 158992$, Aldrich, China), and propargyl alcohol (PA, 99\%, 131452500, Acros, Germany) were purified via vacuum distillation. Tin (II) 2-ethylhexanoate ( $\mathrm{Sn}(\mathrm{Oct})_{2}, 92.5-100 \%$, S3252, Aldrich, Japan) was directly used. Acetonitrile (ACN, $\geq 99.8 \%, 8149$, J. T. Baker, US), tetrahydrofuran (inhibitor-free, for HPLC, $\geq 99.9 \%, 34865$, Aldrich, France), and toluene ( $\geq 99.7 \%, 32249$, Aldrich, France) were distilled from calcium hydride under reduced pressure, before use. All other reagents, as well as solvents, were directly used without further purification. All dialysis tubings with indicated molecular weight cut-off and closures were purchased from Spectrum labs (MWCO 6-8 kDa, Spectra/Por).

\subsection{Characterizations of block-co-polymers and polymeric self-assemblies}

Attenuated total reflectance Fourier transform infrared (ATR-FTIR) spectroscopy measurements were recorded using a Perkin-Elmer Spectrum BX FT-IR spectrometer over the range of $4000-500 \mathrm{~cm}^{-1}$ with a maximum OPD resolution of $1 \mathrm{~cm}^{-1}$.

All proton nuclear magnetic resonance $\left({ }^{1} \mathrm{H}-\mathrm{NMR}\right)$ measurements were carried out on a Varian 600 Spectrometer operating at $599.90 \mathrm{MHz}$. Coupling constant values were given in Hertz, and chemical shifts were reported in $\delta[\mathrm{ppm}]$ with respect to the internal standard TMS. Splitting patterns were described as follows: s (singlet), d (doublet), t (triplet), q (quartet), $\mathrm{m}$ (multiplet), and br (broad signal).

Gel permeation chromatography (GPC) measurements were carried out in two different systems: an Agilent instrument (Model 1100) was used for PCLalkyne, as well as resulting amphiphilic block copolymers, whereas a Viscotek TDA302 GPC instrument was solely used for PEtOx- $\mathrm{N}_{3}$. The Agilent system was equipped with a pump, refractive index (RI), and ultraviolet (UV) detectors and four Waters Styragel columns (guard, HR 5E, HR 4E, HR 3, and HR 2), (4.6 $\mathrm{mm}$ internal diameter, $300 \mathrm{~mm}$ length, packed with $5 \mu \mathrm{m}$ particles) with the effective molecular weight ranges of 2000-4000000, 50$100000,500-30000$, and 500-20000, respectively. The samples were eluted with tetrahydrofuran (THF) at a flow rate of $0.3 \mathrm{ml} / \mathrm{min}$ at $30^{\circ} \mathrm{C}$. The apparent molecular weights $\left(M_{\mathrm{n}, \mathrm{GPC}}\right.$ and $M_{\mathrm{w}, \mathrm{GPC})}$, as well as polydispersity indexes (PDI), were determined upon calibration with linear polystyrene (PS) standards, using PL Caliber Software from Polymer Laboratories. The Viscotek system was equipped with a Viscotek GPCmax pump, refractive index, and rightangle light scattering detectors, and Tosoh TSKGel G3000PWxl (300 mm $\times 7.8 \mathrm{~mm})$ column. Phosphatebuffered saline ( $\mathrm{pH} 7.4,12 \mathrm{mM}$ ) with $0.05 \% \mathrm{NaN}_{3}$ was used as a mobile phase at a flow rate of $0.8 \mathrm{ml} / \mathrm{min}$, and the detectors were calibrated with poly(ethylene oxide) (10 kDa standard solutions). All samples were filtered with $0.2 \mu \mathrm{m}$ regenerated cellulose syringe filters.

The size of polymeric structures $(0.5 \mathrm{mg} / \mathrm{ml})$ was analyzed by dynamic light scattering (DLS) method by using Zetasizer Nano ZS (Malvern Ltd.). The analysis conducted in five replicates and expressed as average. The morphologies of polymeric structures were evaluated by transmission electron microscopy (TEM, FEI Tecnai G2 Spirit) at $80 \mathrm{kV}$, wherein the structures were visualized with negative staining via phosphotungstic acid (PTA) [59].

\subsection{The synthesis of amphiphilic block copolymers}

\subsubsection{The synthesis of azide capped poly(2-ethyl-2-oxazoline) (PEtOx- $\left.\mathrm{N}_{3}\right)$ (3a-b) $[49,60]$}

A flask equipped with a stirring bar was preheated with a heat gun. Then, the flask was capped with a rubber septum, and it was once again heated with a heat gun under vacuum. After cooling down to room temperature under vacuum, the flask was charged with a solution of 2-ethyl-2-oxazoline (1) $(10 \mathrm{ml}$, $99.06 \mathrm{mmol}$ for both PEtOx 2000 , and PEtOx 4000$)$, and methyl $p$-toluenesulfonate (2) $(747 \mu \mathrm{l}, 4.95 \mathrm{mmol}$ for $\mathrm{PEtOx}_{2000}$, and $373 \mu \mathrm{l}, 2.47 \mathrm{mmol}$ for $\mathrm{PEtOx}_{4000}$ ) in acetonitrile $(30 \mathrm{ml})$ under an inert atmosphere at room temperature. After polymerization for 15 hours at $130^{\circ} \mathrm{C}$, the reaction mixture was cooled to room 
temperature, and then, sodium azide $(1.29 \mathrm{~g}$, $19.80 \mathrm{mmol}_{\text {for }} \mathrm{PEtOx}_{2000}$, and $0.64 \mathrm{~g}, 9.88 \mathrm{mmol}$ for $\mathrm{PEtO}_{4000}$ ) was added as a powder in one portion, and the reaction was further stirred for 24 hours at $65^{\circ} \mathrm{C}$ in the dark to terminate the polymerization reaction. The reaction mixture was cooled down to room temperature and the solvent was removed under reduced pressure. Then, the crude material was dissolved in dichloromethane $(10 \mathrm{ml})$. The product was precipitated from the excess amount of cold ether and dried under vacuum overnight. Molecular weight characteristics of the $\mathrm{PEtOx}-\mathrm{N}_{3}$ homopolymers were summarized in Table 1.

${ }^{1} \mathrm{H}-\mathrm{NMR}\left(\mathrm{CDCl}_{3}\right): \delta 3.5-3.3\left(4 \mathrm{H},-\mathrm{N}-\mathrm{CH}_{2}-\mathrm{CH}_{2}-\right)$, 3.0-2.9 (3H, CH $\left.-\mathrm{N}-\mathrm{CH}_{2}-\mathrm{CH}_{2}-\mathrm{N}-\right), 2.4-2.2(2 \mathrm{H}$, $\left.-\mathrm{N}-\mathrm{CO}-\mathrm{CH}_{2}-\mathrm{CH}_{3}\right), 1.1-0.9\left(3 \mathrm{H},-\mathrm{N}-\mathrm{CO}-\mathrm{CH}_{2}-\mathrm{CH}_{3}\right)$. FT-IR (ATR): $v$ [ $\left.\mathrm{cm}^{-1}\right] 2100$ (azide) and 1630 (carbonyl).

\subsubsection{The synthesis of alkyne end-functionalized poly(E-caprolactone) (PCL-alkyne) (6a-f)}

PCL-alkyne (6) was synthesized through ring-opening polymerization of $\varepsilon$-caprolactone (4) (CL) in the presence of $\mathrm{Sn}(\mathrm{Oct})_{2}$, and propargyl alcohol (5), as the catalyst, and the initiator, respectively. CL $(10 \mathrm{ml}$, 90.24 mmol for $\mathrm{PCL}_{4000}, \mathrm{PCL}_{6000}, \mathrm{PCL}_{8000}, \mathrm{PCL}_{10000}$, $\mathrm{PCL}_{12000}$ and $\mathrm{PCL}_{14000}$ ), and propargyl alcohol (PA, $278 \mu \mathrm{l}, 5.15 \mathrm{mmol}$ for $\mathrm{PCL}_{4000} ; 159 \mu 1,2.94 \mathrm{mmol}$ for $\mathrm{PCL}_{6000} ; 111 \mu \mathrm{l}, 2.06 \mathrm{mmol}$ for $\mathrm{PCL}_{8000} ; 100 \mu \mathrm{l}$, $1.72 \mathrm{mmol}$ for $\mathrm{PCL}_{10000} ; 86 \mu 1,1.47 \mathrm{mmol}$ for $\mathrm{PCL}_{12000} ; 75 \mu \mathrm{l}, 1.29 \mathrm{mmol}$ for $\mathrm{PCL}_{14000}$ ) were added and a solution of $\mathrm{Sn}(\mathrm{Oct})_{2}(24.94 \mu \mathrm{l}, 0.077 \mathrm{mmol}$ for $\mathrm{PCL}_{4000}, \mathrm{PCL}_{6000}, \mathrm{PCL}_{8000}, \mathrm{PCL}_{10000}, \mathrm{PCL}_{12000}$ and $\left.\mathrm{PCL}_{14000}\right)$ in toluene $(10 \mathrm{ml})$ was introduced. Then, the reaction mixture was deaerated with nitrogen and then immediately immersed in a thermostatic oil bath at $120^{\circ} \mathrm{C}$ for $5 \mathrm{~h}$. Upon the completion of the polymerization reaction, the solvent was removed under reduced pressure, and the crude material was dissolved in dichloromethane $(10 \mathrm{ml})$. The product was precipitated from the excess amount of cold methanol and dried under vacuum oven overnight at room temperature [60]. Molecular weight characteristics of the PCL-alkyne homopolymers were summarized in Table 2.

${ }^{1} \mathrm{H}-\mathrm{NMR}\left(\mathrm{CDCl}_{3}\right): \delta 4.66\left(\mathrm{~s}, 2 \mathrm{H}, \mathrm{CH}_{2}-\mathrm{C} \equiv \mathrm{CH}\right), 4.00$ (m, $\mathrm{CH}_{2} \mathrm{O}$ on PCL), 3.65 (t, 2H, $\left.\mathrm{CH}_{2} \mathrm{OH}\right), 2.50$ (s, $\left.1 \mathrm{H}, \mathrm{CH}_{2}-\mathrm{C} \equiv \mathrm{CH}\right), 2.35-2.27\left(\mathrm{~m}, \mathrm{CH}_{2} \mathrm{C}=\mathrm{O}\right.$ on $\left.\mathrm{PCL}\right)$, $1.67-1.57$ ( $\mathrm{m}, \mathrm{CH}_{2}$ on PCL), $1.40-1.38$ (m, $\mathrm{CH}_{2}$ on PCL). FT-IR (ATR): $v\left[\mathrm{~cm}^{-1}\right]$ 3265, 2945, 2865, 1730, 1460, 1410, 1390, 1365, 1295, 1245, 1165, $1105,1045,1005,960,730$.

\subsubsection{The synthesis of PEtOx-b-PCL amphiphilic block copolymers (7a-f)}

A flask, equipped with a stirring bar, was capped with a rubber septum and dried with a heat gun under vacuum. In this flask, $\mathrm{PEtOx}^{-\mathrm{N}_{3}}$ (3a-3b) $(0.13 \mathrm{mmol})$, PCL-alkyne (6a-6f) $(0.13 \mathrm{mmol})$, copper sulfate $(0.13 \mathrm{mmol})$, and ascorbic acid $(0.65 \mathrm{mmol})$ were dissolved in dichloromethane $(20 \mathrm{ml})$. The reaction mixture was deaerated through bubbling with nitrogen for 5 minutes, then, the reaction was stirred at room temperature and in the dark for 24 hours. Upon the completion of the reaction, the reaction mixture was passed through a silica column to remove undissolved materials, and the solvent was removed under reduced pressure. The resulting crude material was

Table 1. Molecular weight characteristics of the PEtOx- $\mathrm{N}_{3}$ homopolymers.

\begin{tabular}{|c|c|c|c|c|c|}
\hline $\begin{array}{c}\text { PEtOx-N } \\
\text { homopolymers }\end{array}$ & $\begin{array}{c}\text { Yield } \\
{[\mathbf{g} / \% \mathbf{o}}\end{array}$ & $\begin{array}{c}\boldsymbol{M}_{\mathbf{n}, \text { theo }} \\
{[\mathbf{D a}]}\end{array}$ & $\begin{array}{c}\boldsymbol{M}_{\mathbf{n}, \mathbf{G P C}} \\
{[\mathbf{D a}]}\end{array}$ & $\begin{array}{c}\boldsymbol{M}_{\mathbf{w}, \mathbf{G P C}} \\
{[\mathbf{D a}]}\end{array}$ & $\begin{array}{c}\text { PDI } \\
\left(\boldsymbol{M}_{\mathbf{w}} / \boldsymbol{M}_{\mathbf{n}}\right)\end{array}$ \\
\hline PEtOx $\left._{2000} \mathbf{3 a}\right)$ & $8.94 / 91$ & 1800 & 2000 & 2200 & 1.10 \\
\hline PEtOx $\left._{4000} \mathbf{3 b}\right)$ & $9.13 / 93$ & 3700 & 4000 & 4300 & 1.07 \\
\hline
\end{tabular}

Table 2. Molecular weight characteristics of the PCL-alkyne homopolymers.

\begin{tabular}{|lc|c|c|c|c|c|}
\hline \multicolumn{2}{|c|}{$\begin{array}{c}\text { PCL-alkyne } \\
\text { homopolymers }\end{array}$} & $\begin{array}{c}\text { Yield } \\
{[\mathbf{g} / \% \mathbf{l}}\end{array}$ & $\begin{array}{c}\boldsymbol{M}_{\mathbf{n}, \text { theo }} \\
{[\mathbf{D a}]}\end{array}$ & $\begin{array}{c}\boldsymbol{M}_{\mathbf{n}, \mathbf{G P C}} \\
{[\mathbf{D a}]}\end{array}$ & $\begin{array}{c}\boldsymbol{M}_{\mathbf{w}, \mathbf{G P C}} \\
{[\mathbf{D a}]}\end{array}$ & $\begin{array}{c}\text { PDI } \\
\left(\boldsymbol{M}_{\mathbf{w}} / \boldsymbol{M}_{\mathbf{n}}\right)\end{array}$ \\
\hline $\mathrm{PCL}_{4000}$ & $\mathbf{( 6 a )}$ & $8.65 / 84$ & 1700 & 4000 & 5400 & 1.35 \\
\hline $\mathrm{PCL}_{6000}$ & $\mathbf{( 6 b )}$ & $8.86 / 86$ & 3000 & 6000 & 7900 & 1.31 \\
\hline $\mathrm{PCL}_{8000}$ & $\mathbf{( 6 c )}$ & $8.34 / 81$ & 4100 & 8000 & 10200 & 1.27 \\
\hline $\mathrm{PCL}_{10000}$ & $\mathbf{( 6 d )}$ & $8.24 / 80$ & 4800 & 10000 & 12900 & 1.29 \\
\hline $\mathrm{PCL}_{12000}$ & $\mathbf{6 e})$ & $9.06 / 88$ & 6200 & 12000 & 16100 & 1.34 \\
\hline $\mathrm{PCL}_{14000}$ & $\mathbf{( 6 f )}$ & $9.27 / 90$ & 7200 & 14000 & 19200 & 1.37 \\
\hline
\end{tabular}


dissolved in dichloromethane $(10 \mathrm{ml})$, and the product was precipitated from an excess amount of cold ether. Then, the title compound was isolated with suction and dried under vacuum for overnight (the thorough structural characterizations of $\mathbf{7 a - 7 f}$ are reported in the discussion part) $[49,60]$.

\subsection{Self-assembly process}

Self-assemblies were obtained via the solvent-switch method that relies on the controlled mixing of copolymer solution with aqueous solution [57]. In a typical experiment, PEtOx- $b$-PCL amphiphilic block copolymer $(10 \mathrm{mg})$ was dissolved in THF $(1 \mathrm{ml})$ and was stirred overnight. Once a clear solution is obtained, an aliquot of PBS buffer (pH 7.4, $3 \mathrm{ml}, 12 \mathrm{mM}$ ) was injected into a vigorously stirring copolymer solution at $1 \mathrm{ml} / \mathrm{h}$ rate with a syringe pump, and the polymeric dispersion was obtained. Afterward, the formed polymeric dispersion was placed into a dialysis tube (MWCO 6-8 kDa) and dialyzed against PBS ( $\mathrm{pH}=$ 7.4, 1 1); the external buffer solution was replaced by fresh PBS three times (minimum $4 \mathrm{~h}$ intervals) to remove THF. Afterward, the resulting dispersion was subjected to three cycles of freeze-thaw, at -77 and $37^{\circ} \mathrm{C}$, respectively, to stabilize the products. In the final step, the dispersion was centrifuged at $800 \times \mathrm{G}$ for $5 \mathrm{~min}$ to remove any impurities, and the final product was stored at $+4^{\circ} \mathrm{C}$, until use. The morphologies of the self-assemblies were monitored by using transmission electron microscopy (TEM) [59]. Briefly, $5 \mu 1$ of polymeric dispersion $(0.5 \mathrm{mg} / \mathrm{ml})$ was deposited onto carbon-coated grids for $1 \mathrm{~min}$ then treated with $0.75 \%(\mathrm{w} / \mathrm{v})$ PTA staining solution at $\mathrm{pH}=7.4$ for 10 seconds. The excess amount of solutions was blotted with filter paper, and the samples were dried under vacuum.

\section{Results and discussion}

In designing the chemical architecture of amphiphilic block copolymers which can self-assemble in solution, a variety of distinct self-assembled morphologies including worms, micelles, vesicles, rods, and spheres could be formed, and these studies (nonbiodegradable copolymers [42-44], biodegradable copolymers $[45,46])$ have been reported in the literature. It is well known that several studies indicated that the shape and size of the self-assembled morphologies depend on used solution conditions and polymer properties such as the nature of repeating unit, the molecular weight or the relative block length. Moreover, the ability to control the morphology and dimensions of self-assembled structures fabricated from a given copolymer was investigated by adjusting the solution conditions. The aforementioned morphogenic factors comprise the solvent nature and composition, the water content in the solvent mixture, the polymer concentration and the presence of additives (ions, surfactants, and homopolymer) [47]. Herein, for the first time, we have demonstrated the morphological transitions of PEtOx- $b$-PCL copolymers in aqueous solution by adjusting the nature of the repeating unit, molecular weight, and the relative block length.

Therefore, we have investigated the self-assembly behavior of PEtOx- $b$-PCL copolymers having a molecular weight between 6.7-20.9 $\mathrm{kDa}$ and have monitored different PEtOx- $b$-PCL morphologies, which were attained by taking advantage of these block copolymers where the $f_{\text {hydrophilic }}$ value is in the range of $0.2-0.3$ [35-40], via same self-assembly procedure, depending on the molecular architecture of the copolymer [48]. Several nanostructures were obtained, including ellipsoids, rods, and intermediate structures, which have a broad application area, especially in the biomedical field ranging from drug/ biomacromolecule delivery to protocell development. In particular, since the shape properties of ellipsoid structures are known to provide enhanced cellular phagocytosis [61], the utilization of PEtOx$b$-PCL ellipsoids as intracellular cargo delivery vehicles might be advantageous.

In regards to the morphology of self-assemblies, the hydrophobic/hydrophilic balance of copolymer blocks ( $f_{\text {hydrophilic }}$, for short or simply $f$ ) is decisive. To characterize the CNs-based architectures, it is, therefore, necessary to evaluate the amphiphilic copolymer nature individually, in terms of $f_{\text {hydrophilic }}$. The copolymers having varied $f_{\text {hydrophilic }}$ values such as 0.25-0.45 for PEG-PLA [48], 0.12-0.32 for PEGpoly(caprolactone) [62, 63], 0.31-0.34 for poly(butadiene)-poly(ethylene oxide) [64], 0.42 for hyaluronan-poly (g-benzyl-L-glutamate) [65], 0.25 for polystyrene-poly(acrylic acid) [66], 0.36 for poly[oligo (ethylene glycol)methyl methacrylate]-poly(2-(diisopropylamino)ethyl methacrylate) [67], have been reported to be self-assembled to form CNs. In compliance with these observations, we envisioned to prepare PEtOx- $b$-PCL 7a-7f with $f_{\text {hydrophilic }}$ (or $f_{\mathrm{PEtOx}}$, 
in our case) in this range (Table 3 ) to investigate their morphological transition through transmission electron microscopy (TEM) (Figure 15).

Our synthetic route to access $\mathbf{7 a - 7 f}$, which is summarized in Figure 2, relied on the independent synthesis of PEtOx- $\mathrm{N}_{3}$ and PCL-alkyne blocks, followed by their assembly through copper-catalyzed azide-alkyne cycloaddition (CuAAC) click chemistry [49, 60]. Therein, $\mathrm{PEtOx}-\mathrm{N}_{3} \mathbf{3 a - 3} \mathbf{b}$ was prepared by living cationic ring-opening polymerization (CROP) of 2-ethyl-2-oxazoline whilst PCL-alkyne 6a-6f was synthesized via the coordination-insertion ring-opening polymerization of $\varepsilon$-caprolactone. In the final step, 7a-7f was obtained through the CuAAC reaction between these two polymers $[68,69]$. The relative amounts of the precursors and the reactants, in tandem with the overall yield of the reactions, are given below (Table 3 ).

In this synthetic route, the living CROP of 2-ethyl2 -oxazoline was initiated by methyl $p$-toluenesulfonate (monomer to initiator concentrations $[\mathrm{M}] /[\mathrm{I}]$ were 40:1 and 20:1 for PEtOx 4000 and PEtOx 2000 , respectively) and was terminated with an excess amount of sodium azide [53]. The number-average molecular weights $\left(M_{\mathrm{n}}\right)$ of PEtOx- $\mathrm{N}_{3}$ blocks 3a-3b were measured by gel permeation chromatography and were found to be $4000 \mathrm{Da}(\mathrm{PDI}=1.07), 2000 \mathrm{Da}$ $(\mathrm{PDI}=1.10)$, respectively (Figure 3$)$. On the other hand, clickable PCL-alkyne 6a-6f were prepared by coordination-insertion ROP of $\varepsilon$-caprolactone, using

Table 3. The relative amounts of the precursors and the reactants used in the synthesis of amphiphilic block copolymers.

\begin{tabular}{|c|c|c|c|c|c|c|c|}
\hline \multicolumn{2}{|c|}{ Amphiphilic block copolymers } & \multirow{2}{*}{$\begin{array}{c}\boldsymbol{f}_{\text {PEtOx }} \\
0.20\end{array}$} & \multirow{2}{*}{$\begin{array}{c}\begin{array}{c}\text { PEtOx (3a-3b) } \\
\text { [mmol/g] }\end{array} \\
0.13 / 0.26 \\
\end{array}$} & \multirow{2}{*}{$\begin{array}{c}\begin{array}{c}\text { PCL(6a-6f) } \\
\text { [mmol/g] }\end{array} \\
0.13 / 1.00\end{array}$} & \multirow{2}{*}{$\begin{array}{c}\begin{array}{c}\mathrm{CuSO}_{4} \\
{[\mathrm{mmol} / \mathrm{g}]}\end{array} \\
0.13 / 0.02\end{array}$} & \multirow{2}{*}{$\begin{array}{c}\begin{array}{c}\text { Ascorbic acid } \\
{[\mathrm{mmol} / \mathrm{g}]}\end{array} \\
0.65 / 0.12 \\
\end{array}$} & \multirow{2}{*}{$\begin{array}{c}\begin{array}{c}\text { Yield } \\
{[\% / g]}\end{array} \\
84 / 1.05\end{array}$} \\
\hline $\mathrm{PEtOx}_{2000}-b-\mathrm{PCL}_{8000}$ & $(7 \mathbf{a})$ & & & & & & \\
\hline $\mathrm{PEtOx}_{2000}-b-\mathrm{PCL}_{6000}$ & $(7 b)$ & 0.25 & $0.17 / 0.34$ & $0.17 / 1.00$ & $0.17 / 0.03$ & $0.85 / 0.15$ & $79 / 1.06$ \\
\hline $\mathrm{PEtO}_{2000}-b-\mathrm{PCL}_{4000}$ & $(7 \mathrm{c})$ & 0.33 & $0.25 / 0.50$ & $0.25 / 1.00$ & $0.25 / 0.04$ & $1.25 / 0.22$ & $84 / 1.26$ \\
\hline $\mathrm{PEtO}_{4000}-b-\mathrm{PCL}_{14000}$ & $(7 d)$ & 0.22 & $0.07 / 0.28$ & $0.07 / 1.00$ & $0.07 / 0.01$ & $0.35 / 0.06$ & $78 / 1.00$ \\
\hline $\mathrm{PEtOx}_{4000}-b-\mathrm{PCL}_{12000}$ & $(7 \mathbf{e})$ & 0.25 & $0.08 / 0.32$ & $0.08 / 1.00$ & $0.08 / 0.01$ & $0.40 / 0.07$ & $85 / 1.12$ \\
\hline $\mathrm{PEtO}_{4000}-b-\mathrm{PCL}_{10000}$ & $(7 f)$ & 0.29 & $0.10 / 0.40$ & $0.10 / 1.00$ & $0.10 / 0.02$ & $0.50 / 0.09$ & $77 / 1.08$ \\
\hline
\end{tabular}
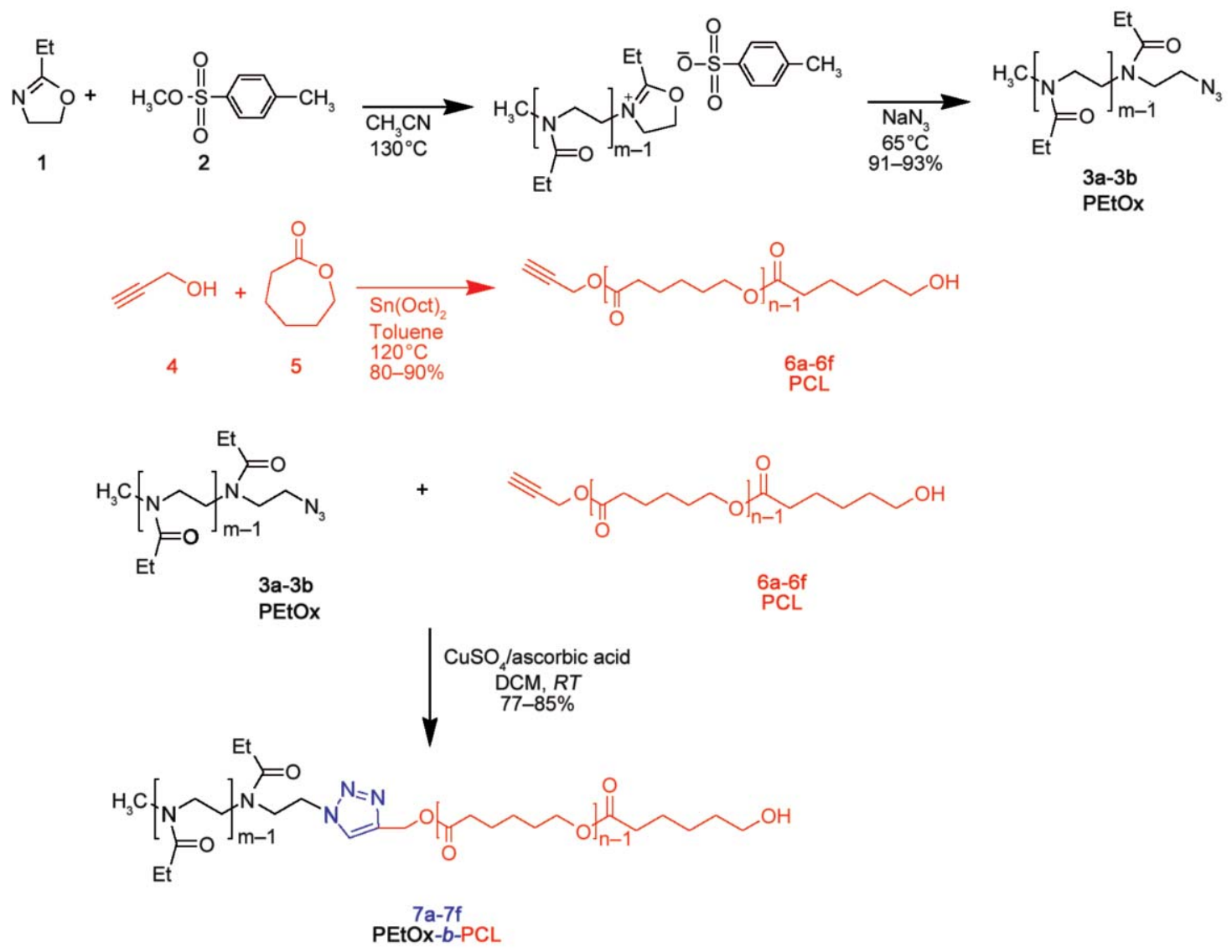

Figure 2. The synthetic route to PEtOx- $b$-PCL amphiphilic block copolymers 7a-7f. 


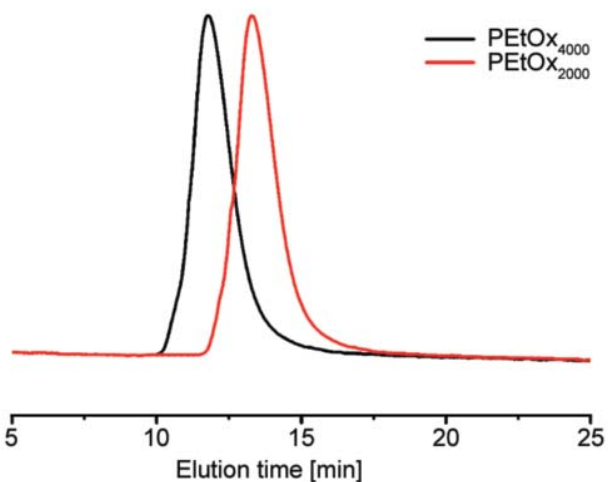

Figure 3. GPC chromatograms of PEtOx 2000 and PEtOx 4000 .

$\mathrm{Sn}(\mathrm{Oct})_{2}$ as catalyst and propargyl alcohol as initiator $\left([\mathrm{M}] /[\mathrm{I}]=18,31,44,53,62\right.$, and 70 for $\mathrm{PCL}_{4000}$, PCL6000, PCL $8000, \mathrm{PCL}_{10000}, \mathrm{PCL}_{12000}$ and $\mathrm{PCL}_{14000}$, respectively). According to GPC analysis, $M_{\mathrm{n}}$ values of PCL-alkyne polymers were found to be $4000 \mathrm{Da} \quad(\mathrm{PDI}=1.35), 6000 \mathrm{Da} \quad(\mathrm{PDI}=1.31)$, $8000 \mathrm{Da}(\mathrm{PDI}=1.27), 10000 \mathrm{Da}(\mathrm{PDI}=1.29)$, $12000 \mathrm{Da}(\mathrm{PDI}=1.34), 14000 \mathrm{Da}(\mathrm{PDI}=1.37)$, respectively (Figure 4). The structures of $\mathbf{3 a - 3} \mathbf{b}$ and $\mathbf{6 a -}$ 6f were also confirmed by FT-IR (Figures 5 and 6), ${ }^{1} \mathrm{H}-\mathrm{NMR}$ (Figures 7 and 8), and they are in concert with our previous results $[49,60]$. In the final step, the CuAAC click reactions of $\mathbf{3 a - 3} \mathbf{b}$ with $\mathbf{6 a - 6 \mathbf { f }}$ $\left(\left[\mathrm{PEtOx}-\mathrm{N}_{3}\right]:[\mathrm{PCL}-\mathrm{alkyne}]=1: 1\right)$ at room temperature

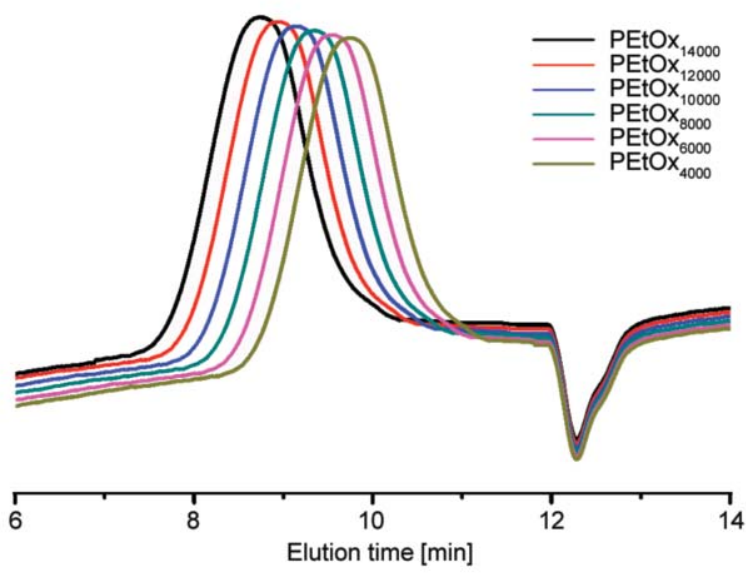

Figure 4. GPC chromatograms of $\mathrm{PCL}_{4000}, \mathrm{PCL}_{6000}, \mathrm{PCL}_{8000}$, $\mathrm{PCL}_{10000}, \mathrm{PCL}_{12000}$ and $\mathrm{PEtOx}_{14000}$.

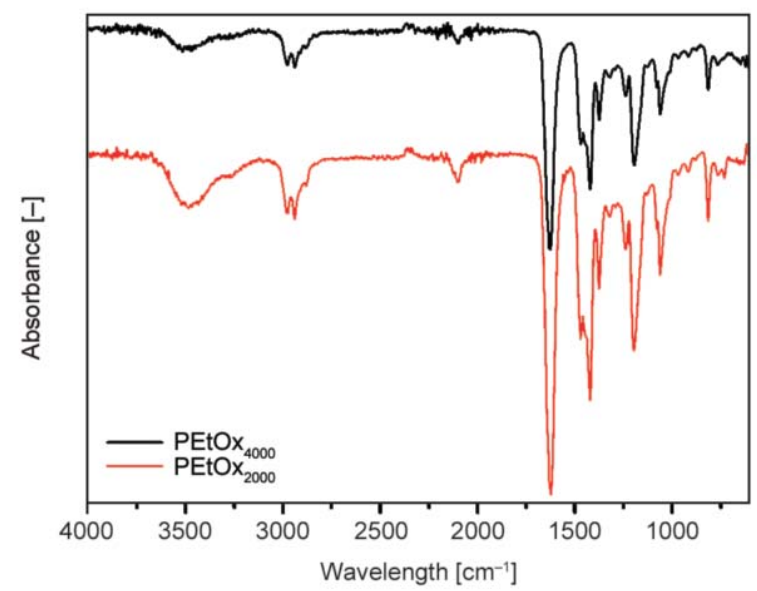

Figure 5. FT-IR spectra of $\mathrm{PEtOx}_{2000}$ and $\mathrm{PEtOx}_{4000}$.

afforded 7a-7f, as detailed in the experimental section. The molecular weights of the precursors and the resulting block copolymers, their PDI and $f_{\text {PEtOx }}$ for 7a-7f were summarized in Table 4.

$\mathrm{CuAAC}$ click reactions are monitored through FTIR, wherein the azide band of PEtOx- $\mathrm{N}_{3}$ at $2100 \mathrm{~cm}^{-1}$ and alkyne bands $(\mathrm{C} \equiv \mathrm{C}$ and $\mathrm{C} \equiv \mathrm{C}-\mathrm{H})$ of PCL-alkyne at 2125 and $3320 \mathrm{~cm}^{-1}$ disappeared, whereas new peaks corresponding to $\mathrm{C}=\mathrm{O}$ and $\mathrm{C}-\mathrm{O}-\mathrm{C}$ bonds of ether groups on PCL emerged at 1728 and $1240 \mathrm{~cm}^{-1}$, respectively. In addition, the distinctive amide, methine, methylene, and methyl bands of PEtOx were

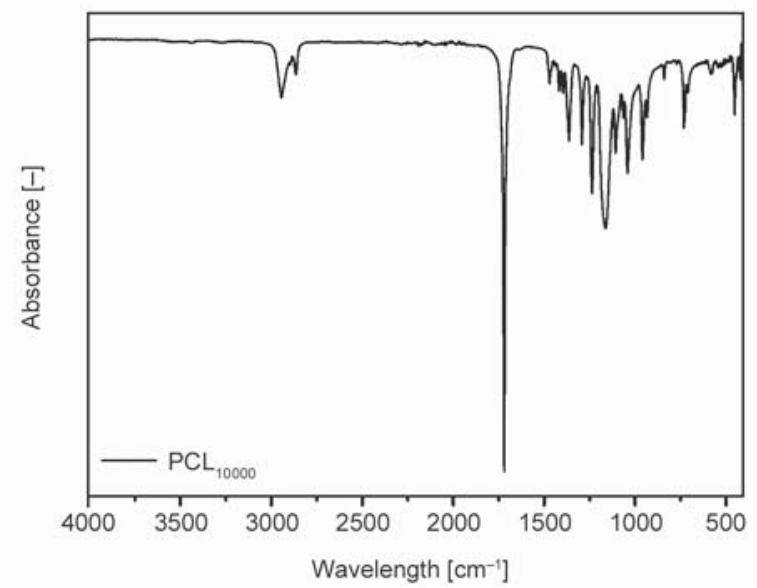

Figure 6. FT-IR spectrum of $\mathrm{PCL}_{10000}$.

Table 4. The molecular weights of the precursors and resulting amphiphilic block copolymers, as well as $f_{\mathrm{PEtOx}}$.

\begin{tabular}{|c|c|c|c|c|c|c|c|c|c|c|}
\hline \multirow{2}{*}{ Amphiphilic block copolymers } & \multicolumn{3}{|c|}{ PEtOx (3a-3b) } & \multicolumn{3}{|c|}{ PCL (6a-6f) } & \multicolumn{4}{|c|}{ PEtOx-b-PCL (7a-7f) } \\
\hline & $M_{\mathrm{n}}$ & $M_{\mathrm{w}}$ & PDI & $M_{\mathrm{n}}$ & $M_{\mathrm{w}}$ & PDI & $M_{\mathrm{n}}$ & $M_{\mathrm{w}}$ & PDI & $f_{\text {PEtOx }}$ \\
\hline $\mathrm{PEtOx}_{2000}-b-\mathrm{PCL}_{8000}$ & 2000 & 2200 & 1.10 & 8000 & 10200 & 1.27 & 8700 & 10500 & 1.21 & 0.20 \\
\hline $\mathrm{PEtOx}_{2000}-b-\mathrm{PCL}_{6000}$ & 2000 & 2200 & 1.10 & 6000 & 7900 & 1.31 & 6900 & 8600 & 1.25 & 0.25 \\
\hline $\mathrm{PEtOx}_{2000}-b-\mathrm{PCL}_{4000}$ & 2000 & 2200 & 1.10 & 4000 & 5400 & 1.35 & 5200 & 6700 & 1.29 & 0.33 \\
\hline $\mathrm{PEtOx}_{4000}-b-\mathrm{PCL}_{14000}$ & 4000 & 4300 & 1.07 & 14000 & 19200 & 1.37 & 16100 & 20900 & 1.30 & 0.22 \\
\hline PEtOx $_{4000}-b-\mathrm{PCL}_{12000}$ & 4000 & 4300 & 1.07 & 12000 & 16100 & 1.34 & 14300 & 18200 & 1.27 & 0.25 \\
\hline $\mathrm{PEtOx}_{4000}-b-\mathrm{PCL}_{10000}$ & 4000 & 4300 & 1.07 & 10000 & 12900 & 1.29 & 12400 & 15100 & 1.22 & 0.29 \\
\hline
\end{tabular}




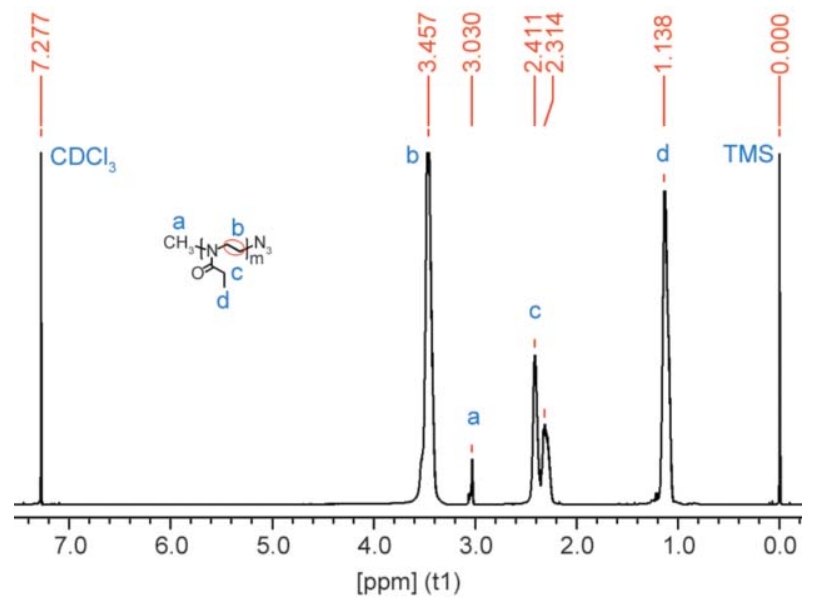

Figure 7. ${ }^{1} \mathrm{H}-\mathrm{NMR}$ spectrum of $\mathrm{PEtOx}-\mathrm{N}_{3}$.

fully assigned in both block copolymer samples (Figures 9 and 10). The final products $7 \mathbf{a}-7 \mathbf{f}$ were also characterized with ${ }^{1} \mathrm{H}-\mathrm{NMR}$; therein, the key evidence is the peak of the triazole ring formed after Click reaction, which appears at ca. $8.0 \mathrm{ppm}$ [60]. Furthermore, the characteristic protons of both PEtOx with PCL segments were fully assigned (Figure 11 for details); however, it is worth noting that the methine $\left(\mathrm{CH}_{2}-\mathrm{C} \equiv \mathrm{CH}\right)$ proton of PCL alkyne protons at $2.4 \mathrm{ppm}$ overlapped with methylene protons of PEtOx (c) and that the methylene $\left(\mathrm{CH}_{2}-\mathrm{C} \equiv \mathrm{CH}\right)$ protons of PCL (h) at $4.6 \mathrm{ppm}$ distinctly shifted to $5.2 \mathrm{ppm}$. Overall, the FT-IR and ${ }^{1} \mathrm{H}-\mathrm{NMR}$ spectra of 7a-7f resonate well with our previous results $[53,60,70]$, and they account for the successful synthesis of the block copolymers through $\mathrm{CuAAC}$ click reaction between PEtOx and PCL blocks.

The GPC analysis of amphiphilic block copolymers also reveals the tethering of both blocks, when compared to those of $\mathbf{3 a - 3} \mathbf{b}$ and $\mathbf{6 a - 6 f}$. The GPC

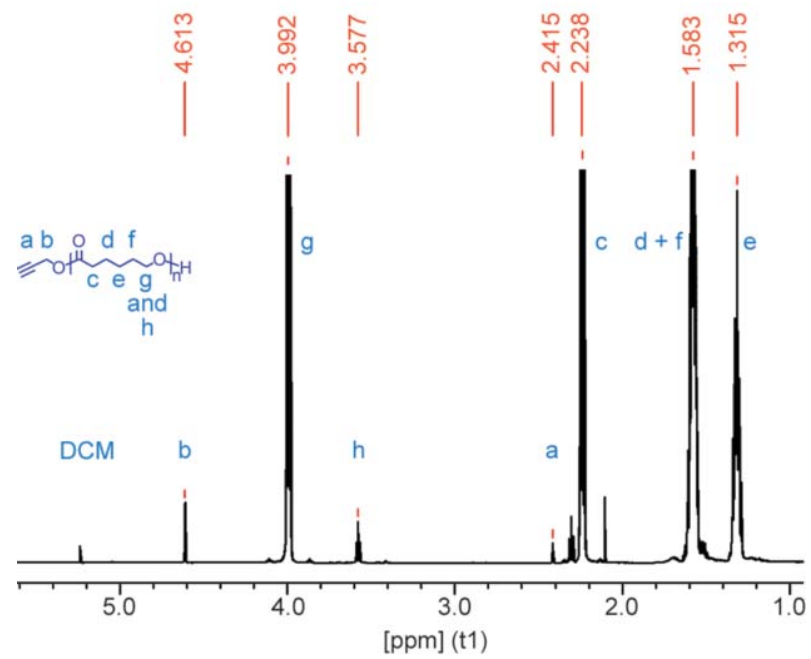

Figure 8. ${ }^{1} \mathrm{H}-\mathrm{NMR}$ spectrum of PCL-alkyne.

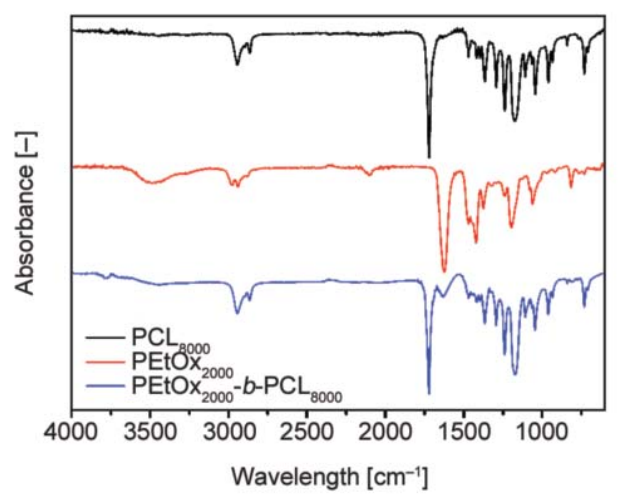

Figure 9. FT-IR spectra of $\mathrm{PEtOx}_{2000}, \mathrm{PCL}_{8000}$ and $\mathrm{PEtOx}_{2000^{-}}$ $b$ - $\mathrm{PCL}_{8000}$.

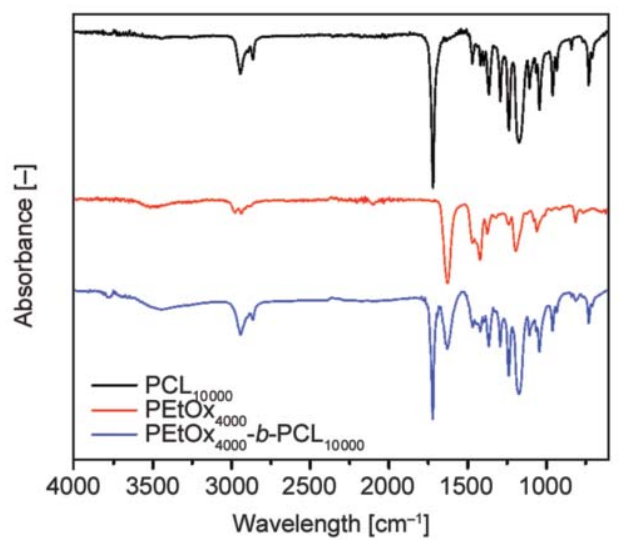

Figure 10. FT-IR spectra of $\mathrm{PEtOx}_{4000}, \mathrm{PCL}_{10000}$ and $\mathrm{PEtOx}_{4000}-b-\mathrm{PCL}_{10000}$

chromatograms of the latter exhibited rather unimodal patterns with narrow molecular weight distributions, which distinctly suggests that control over molecular weight had been achieved through both coordination-insertion ROP and living CROP. Upon the click reactions, the GPC traces of PEtOx- $b$-PCL block copolymers were monomodal and shifted

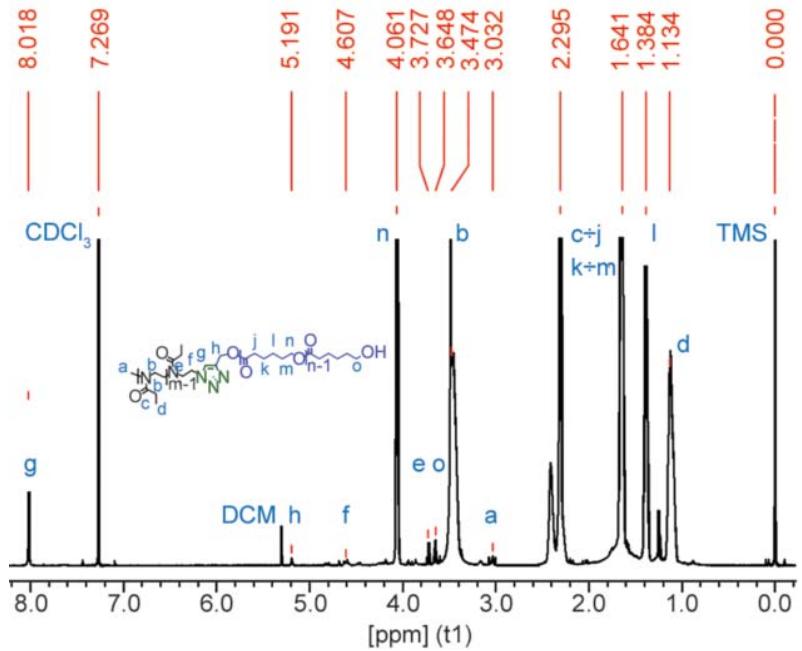

Figure 11. ${ }^{1} \mathrm{H}-\mathrm{NMR}$ spectrum of $\mathrm{PEtOx}-b$-PCL amphiphilic block copolymer. 
towards higher molecular weight regions, as expected (Figures 12 and 13). Of course, the fact that GPC equipment was calibrated with polystyrene standards caused molecular weights of copolymers to exceed theoretical molecular weights to some extent. Yet, an increase in the molecular weights of PEtOx- $b$-PCL block copolymers was apparent in GPC chromatograms, further conforming to the synthesis of 7a-7f. With these amphiphilic block copolymers in hand, copolymeric self-assemblies were obtained via the solvent-switch method that involves the vigorous mixing of amphiphile solution with an aqueous buffer solution [57]. In compliance with the relevant literature, the morphological transitions between these CNs from ellipsoid to rod were observed by altering $f_{\text {PEtOx }}$, and the careful monitoring of CNs via transmission electron microscopy (TEM) revealed the evolution of the particle morphology [41, 43].

In the literature, we, for the first time, investigated the morphological transitions of PEtOx- $b$-PCL amphiphilic block copolymer-based $\mathrm{CNs}$ and observed that PEtOx- $b$-PCL copolymers with $f_{\mathrm{PEtOx}}$ in the range of $0.20-0.30$, self-assemble to form ellipsoidal and/or tubular structures and the obtained CNs were in good agreement with the relevant literature [71-73]. Therein, Table 5 shows that CNs with $329,196,71,222$, 204 and $122 \mathrm{~nm}$ average particle sizes (hydrodynamic radius, $R_{\mathrm{H}}$ ) were obtained from $\mathrm{PEtOx}_{2000}-b-\mathrm{PCL}_{4000}$, $\mathrm{PEtOx}_{2000}-b-\mathrm{PCL}_{6000}, \quad \mathrm{PEtOx}_{2000}-b-\mathrm{PCL}_{8000}$,

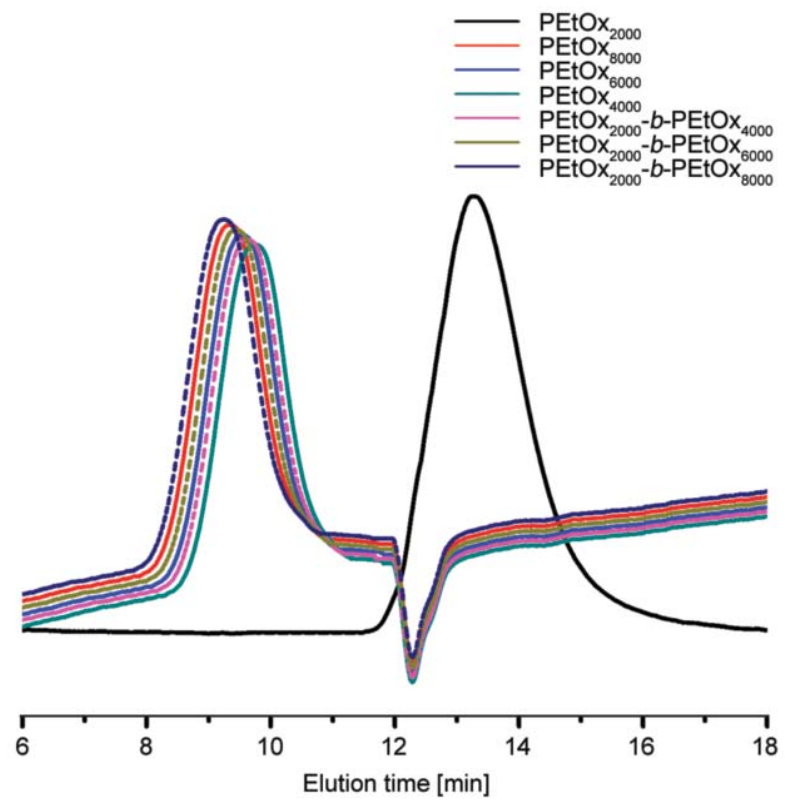

Figure 12. The GPC traces of precursors and resulting $\mathrm{PEtO}_{2000}-b-\mathrm{PCL}_{4000}, \quad \mathrm{PEtOx}_{2000}-b-\mathrm{PCL}_{6000}$, $\mathrm{PEtOx}_{2000}-b-\mathrm{PCL}_{8000}$ amphiphilic block copolymers.
$\mathrm{PEtOx}_{4000}-b-\mathrm{PCL}_{10000}, \mathrm{PEtOx}_{4000}-b-\mathrm{PCL}_{12000}$ and $\mathrm{PEtOx}_{4000}-b-\mathrm{PCL}_{14000}$ copolymers, respectively. The PDI values from $7 \mathbf{a}$ to $7 \mathbf{c}$ vary between 0.14 to 0.54 , which indicates the narrow self-assemblies diameter distribution, whereas the PDI values from $\mathbf{7 d}$ to $7 \mathbf{f}$ diversify between 0.06 to 0.33 .

The fabrication of self-assemblies was carried out via a bottom-up approach (solvent-switch) where copolymer monomers self-assemble to generate thermodynamically stable separate nanoscopic structures [74]. The solvent-switch method, also called solvent displacement or nanoprecipitation, which is usually preferred at fabrication of self-assemblies from copolymers having glassy hydrophobic fraction such as PCL, was utilized to yield CNs at physiological $\mathrm{pH}$ and salt concentration. Afterward, polymeric dispersion was placed into the dialysis tube (MWCO 6-8 kDa, Spectra/Por) and dialyzed against pH 7.4 PBS (1 L); the external buffer solution was replaced by fresh PBS three times (minimum $4 \mathrm{~h}$ intervals), to remove THF.

The data in Figure 14 and Table 5 revealed that increasing $f_{\text {hydrophilic }}$ value causes the formation of larger and then tubular nanostructures, respectively. As the $f_{\text {PEtOx }}$ value increases, it was observed that the $\mathrm{CNs}$ evolve from ellipsoid to rod-like structures. This situation was proved thanks to increment in hydrodynamic diameter. The difference between the width and length of the rod-like structures triggered a wide

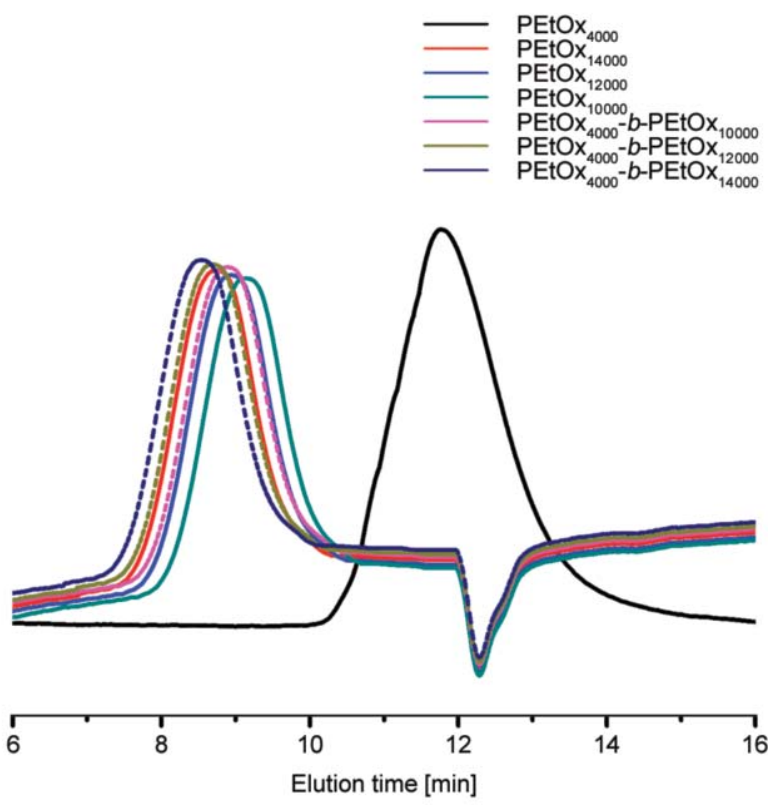

Figure 13. The GPC traces of precursors and resulting $\mathrm{PEtO}_{4000}-b-\mathrm{PCL}_{10000}, \mathrm{PEtOx}_{4000}-b-\mathrm{PCL}_{12000}$, $\mathrm{PEtOx}_{4000}-b-\mathrm{PCL}_{14000}$ amphiphilic block copolymers. 
Table 5. $f_{\mathrm{PEtOx}}$, hydrodynamic radius and PDI values of PEtOx- $b$-PCL self-assemblies.

\begin{tabular}{|ll|c|c|c|}
\hline \multicolumn{2}{|c|}{ Amphiphilic block copolymers } & $\boldsymbol{f}_{\text {PEtOx }}$ & $\begin{array}{c}\boldsymbol{R}_{\mathbf{H}} \\
{[\mathbf{n m}]}\end{array}$ & PDI \\
\hline PEtOx $_{2000}-b-\mathrm{PCL}_{8000}\left(\mathrm{PEtOx}_{20}-b-\mathrm{PCL}_{70}\right)$ & $\mathbf{7 a})$ & 0.20 & $70.71 \pm 1.09$ & $0.137 \pm 0.05$ \\
\hline PEtOx $_{2000}-b-\mathrm{PCL}_{6000}\left(\mathrm{PEtOx}_{20}-b-\mathrm{PCL}_{53}\right)$ & $\mathbf{( 7 b )}$ & 0.25 & $195.70 \pm 2.81$ & $0.226 \pm 0.14$ \\
\hline PEtOx $_{2000}-b-\mathrm{PCL}_{4000}\left(\mathrm{PEtOx}_{20}-b-\mathrm{PCL}_{35}\right)$ & $\mathbf{7})$ & 0.33 & $329.20 \pm 19.52$ & $0.544 \pm 0.21$ \\
\hline PEtOx $_{4000}-b-\mathrm{PCL}_{14000}\left(\mathrm{PEtOx}_{40}-b-\mathrm{PCL}_{123}\right)$ & $\mathbf{( 7 d )}$ & 0.22 & $121.90 \pm 1.06$ & $0.061 \pm 0.02$ \\
\hline PEtOx $_{4000}-b-\mathrm{PCL}_{12000}\left(\mathrm{PEtOx}_{40}-b-\mathrm{PCL}_{105}\right)$ & $\mathbf{( 7 e )}$ & 0.25 & $204.20 \pm 3.10$ & $0.125 \pm 0.08$ \\
\hline PEtOx $_{4000}-b-\mathrm{PCL}_{10000}\left(\mathrm{PEtOx}_{40}-b-\mathrm{PCL}_{88}\right)$ & $\mathbf{( 7 f )}$ & 0.29 & $222.40 \pm 11.72$ & $0.326 \pm 0.17$ \\
\hline
\end{tabular}

distribution of the beam falling on them during the DLS analysis by refracting at very different angles and intensities. As the structures of self-assemblies move away from the ellipsoids, the broader distributed results were obtained. Thus, the nano self-assemblies, like long rods, which obtained by using the $\mathrm{PEtOx}_{2000}-b-\mathrm{PCL}_{4000}$ (7c) copolymer, were demonstrated by a broad DLS profile in Figure 14. Moreover, DLS data in Figure 14 reveal the morphological transition from ellipsoid to rod architectures of prepared copolymeric self-assemblies within 70.71$329.20 \mathrm{~nm}$ and $121.90-222.40 \mathrm{~nm}$ size ranges, in accordance with DLS data for A-C and D-F, respectively [71-73].

Figure 15 also supported our main idea and demonstrated that block copolymer self-assemblies indicate the morphological transition from ellipsoid to rod-like
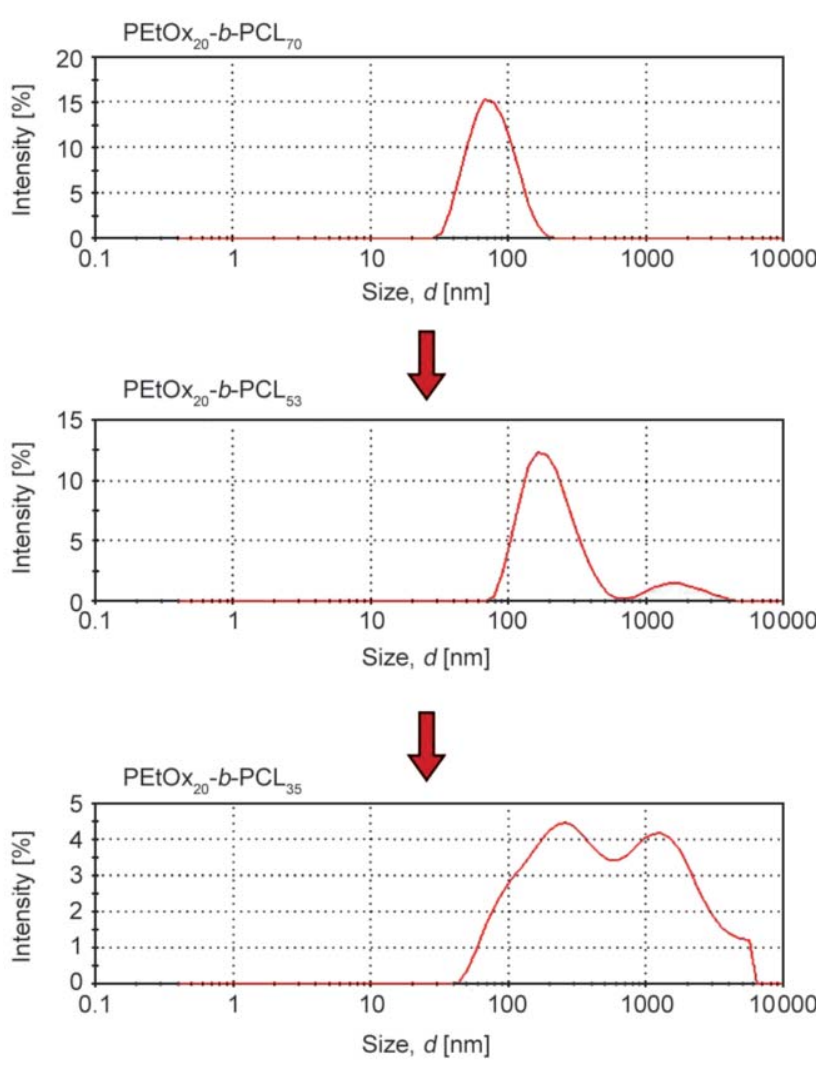

structures owing to the increased $f_{\text {PEtOx }}$ value [7173]. The lengthy rod-like nanostructures were formed by the self-assembly of PEtOx $2000-b-\mathrm{PCL}_{4000}$ (7c) block copolymer, whereas shorter rod-like nano selfassemblies were fabricated by utilizing $\mathrm{PEtOx}_{4000^{-}} b$ $\mathrm{PCL}_{10000}$ (7f) which have similar $f_{\mathrm{PEtOx}}$ value. This is due to the fact that the system energy in the self-assembly process formed the longer rod-like nanostructures by making the hydrophobic PCL block with shorter chain length more easily bent in the $\mathrm{PEtOx}_{2000^{-}}$ $b$ - $\mathrm{PCL}_{4000}$ (7c) block copolymer. However, the same system energy created less elongated rod-like block copolymer self-assemblies by making the hydrophobic PCL block with longer chain length less bent in the $\mathrm{PEtOx}_{4000}-b-\mathrm{PCL}_{10000}$ (7f) block copolymer.

The six different PEtOx- $b$-PCL CNs were analyzed by TEM to assess their morphology (see Figure 15).
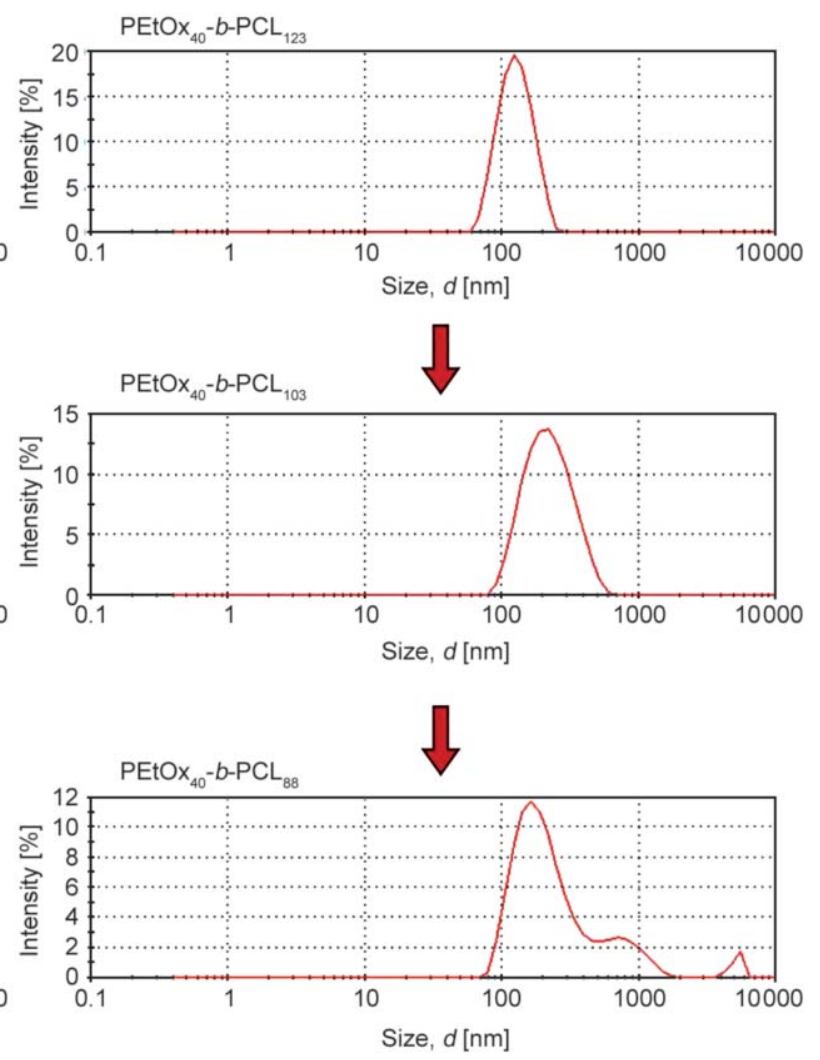

Figure 14. Effect of molecular weight and $f_{\mathrm{PEtOx}}$ value on the size/size distribution of the PEtOx- $b$-PCL self-assemblies. 

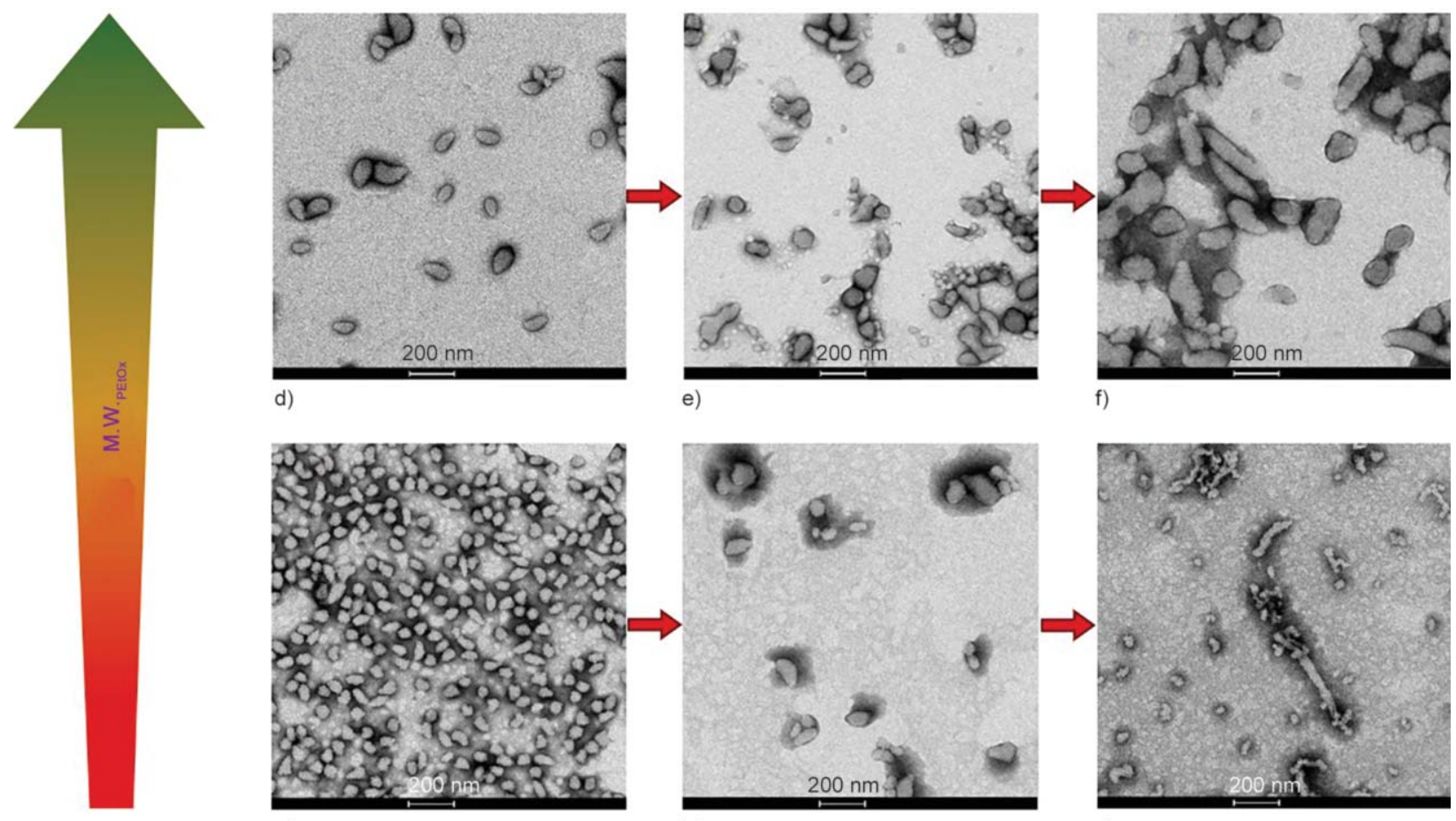

a)

b)

c)

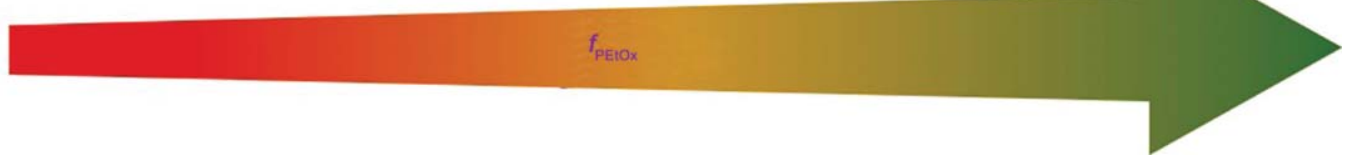

Figure 15. TEM images of self-assembled structures generated from $\mathrm{PEtOx}_{2000}-b-\mathrm{PCL}_{8000}$ (a), $\mathrm{PEtOx}_{2000}-b-\mathrm{PCL}_{6000}$ (b), $\mathrm{PEtOx}_{2000}-b-\mathrm{PCL}_{4000}$ (c), PEtOx $4000-b-\mathrm{PCL}_{14000}$ (d), $\mathrm{PEtOx}_{4000}-b-\mathrm{PCL}_{12000}$ (e) and $\mathrm{PEtOx}_{4000}-b-\mathrm{PCL}_{10000}$ (f).

$\mathrm{PEtOx}_{2000}-b-\mathrm{PCL}_{8000}$ (7a) generated exclusively ellipsoids (see Figure 15a). Decreasing the PCL block length leads to a mixture of (mainly) short, rod particles, and some remaining ellipsoid particles for $\mathrm{PEtOx}_{2000}-b-\mathrm{PCL}_{6000}(\mathbf{7 b})$ (see Figure 15b). Using a block composition of $\mathrm{PEtOx}_{2000}-b-\mathrm{PCL}_{4000}(\mathbf{7 c})$ leads to longer rods, with some ellipsoidal structures (see Figure 15c). On the other hand, when the remaining 3 block copolymeric particles were investigated, an increase of just 20 PEtOx units results in the generation of ellipsoids for $\mathrm{PEtOx}_{4000}-b-\mathrm{PCL}_{14000}$ (7d) (see Figure 15d). $\mathrm{PEtOx}_{4000}-b-\mathrm{PCL}_{12000}$ (7e) forms an intriguing intermediate phase comprising ellipsoid-like particles and small rod-like structures (see Figure 15e). Finally, a pure rod-like structure phase is observed when utilizing $\mathrm{PEtOx}_{4000}-b$ $\mathrm{PCL}_{10000}$ (7f) (see Figure 15f).

As evidenced in Figure 16, when $f_{\text {PEtOx }}$ value of the copolymer is $\sim 0.20$, the ellipsoid-like morphology was observed, whereas the rod-like morphology was detected when $f_{\text {PEtOx }}$ value of the copolymer is $\sim 0.30$. Firstly, the ellipsoid structures closed up each other and then merged. Finally, these structures were transformed into dispersed rod-like structures associated with the increased $f_{\text {PEtOx }}$ value from 0.20 to 0.30 . The lengths of the molecular chains exposed to the same system energy played an important role in the transformation of the ellipsoids. When the copolymers having a similar $f_{\text {PEtOx }}$ value and exposed to the same system energy were examined, it was found that shorter rod-like structures were obtained by using higher chain length copolymers while longer rodlike structures were obtained by the utilization of copolymers having shorter chain length, depending on the ease of molecular flexibility of shorter chain length copolymers.

Figure 16 shows the phase behavior of copolymeric particles as functions of $f_{\mathrm{PEtOx}}$ and molecular weight. For all six block copolymers with different molecular weights, the particle shape and morphology dramatically changed with $f_{\text {PEtOx. }}$. The frequency of particle morphologies (from ellipsoid to rod) was observed for a given molecular weight copolymeric structures and $f_{\text {PEtOx }}$. 


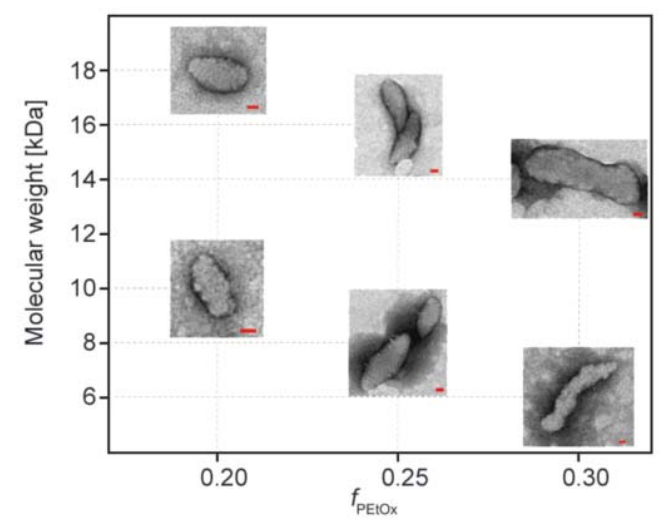

Figure 16. Effect of molecular weight and $f_{\mathrm{PEtOx}}$ value on the morphology of the PEtOx- $b$-PCL self-assemblies (Scales correspond to $20 \mathrm{~nm}$ ).

\section{Conclusions}

We have shown how different $f_{\text {hydrophilic values of the }}$ amphiphilic block copolymers can significantly influence the resulting morphologies of the self-assembled structures. To the best of the authors' knowledge, this is the first investigation for morphological transitions of PEtOx- $b$-PCL amphiphilic block copolymer-based $\mathrm{CNs}$ in the literature. In addition, our findings were concluded that PEtOx- $b$-PCL amphiphilic block copolymer-based CNs including ellipsoids, rods, and intermediate structures would be utilized in the fabrication of new generation biomaterials for important applications such as drug/gene delivery systems, pharmaceutics, and protocell development.

\section{Acknowledgements}

The authors would like to thank the Scientific and Technological Research Council of Turkey (TUBITAK) for financial supports with grant number of 213M725.

\section{References}

[1] Alexandridis P., Lindman B.: Amphiphilic block copolymers-self-assembly and applications. Elsevier, Amsterdam (2000).

[2] Bates F. S., Fredrickson G. H.: Block copolymers-Designer soft materials. Physics Today, 52, 32-38 (1999). https://doi.org/10.1063/1.882522

[3] Förster S., Plantenberg T.: From self-organizing polymers to nanohybrid and biomaterials. Angewandte Chemie, 41, 688-714 (2002).

https://doi.org/10.1002/1521-

3773(20020301)41:5<688::AID-ANIE688>3.0.CO;2-3

[4] Kim J. K., Yang S. Y., Lee Y., Kim Y.: Functional nanomaterials based on block copolymer self-assembly. Progress in Polymer Science, 35, 1325-1349 (2010). https://doi.org/10.1016/j.progpolymsci.2010.06.002
[5] Orilall M. C., Wiesner U.: Block copolymer based composition and morphology control in nanostructured hybrid materials for energy conversion and storage: Solar cells, batteries, and fuel cells. Chemical Society Reviews, 40, 520-535 (2011). https://doi.org/10.1039/C0CS00034E

[6] van Hest J. C. M., Delnoye D. A. P., Baars M. W. P. L., van Genderen M. H. P., Meijer E. W.: Polystyrene-dendrimer amphiphilic block copolymers with a generation-dependent aggregation. Science, 268, 1592-1595 (1995). https://doi.org/10.1126/science.268.5217.1592

[7] Zhang L., Eisenberg A.: Multiple morphologies of 'crew-cut' aggregates of polystyrene- $b$-poly(acrylic acid) block copolymers. Science, 268, 1728-1731 (1995). https://doi.org/10.1126/science.268.5218.1728

[8] Zhang L., Yu K., Eisenberg A.: Ion-induced morphological changes in 'crew-cut' aggregates of amphiphilic block copolymers. Science, 272, 1777-1779 (1996). https://doi.org/10.1126/science.272.5269.1777

[9] Balmbra R. R., Clunie J. S., Goodman J. F.: Cubic mesomorphic phases. Nature, 222, 1159-1160 (1969). https://doi.org/10.1038/2221159a0

[10] Israelachvili J. N.: Intermolecular and surface forces. Academic Press, London (1991).

[11] Israelachvili J. N., Mitchell D. J., Ninham B. W. J.: Theory of self-assembly of hydrocarbon amphiphiles into micelles and bilayers. Journal of the Chemical Society, Faraday Transactions 2: Molecular and Chemical Physics, 72, 1525-1568 (1976). https://doi.org/10.1039/F29767201525

[12] Shin J. M., Kim Y. J., Yun H., Yi G-R., Kim B. J.: Morphological evolution of block copolymer particles: Effect of solvent evaporation rate on particle shape and morphology. ACS Nano, 11, 2133-2142 (2017). https://doi.org/10.1021/acsnano.6b08342

[13] Robertson J. D., Yealland G., Avila-Olias M., Chierico L., Bandmann O., Renshaw S. A., Battaglia G.: pH-sensitive tubular polymersomes: Formation and applications in cellular delivery. ACS Nano, 8, 4650-4661 (2014). https://doi.org/10.1021/nn5004088

[14] Won Y-Y., Davis H. T., Bates F. S.: Giant wormlike rubber micelles. Science, 283, 960-963 (1999). https://doi.org/10.1126/science.283.5404.960

[15] Li Z., Kesselman E., Talmon Y., Hillmyer M. A., Lodge T. P.: Multicompartment micelles from ABC miktoarm stars in water. Science, 306, 98-101 (2004). https://doi.org/10.1126/science.1103350

[16] Cui H., Chen Z., Zhong S., Wooley K. L., Pochan D. J.: Block copolymer assembly via kinetic control. Science, 317, 647-650 (2007). https://doi.org/10.1126/science. 1141768 
[17] Wang X., Guerin G., Wang H., Wang Y., Manners I., Winnik M. A.: Cylindrical block copolymer micelles and $c o$-micelles of controlled length and architecture. Science, 317, 644-647 (2007).

https://doi.org/10.1126/science.1141382

[18] Jain S., Bates F. S.: On the origins of morphological complexity in block copolymer surfactants. Science, 300, 460-464 (2003). https://doi.org/10.1126/science. 1082193

[19] Pochan D. J., Chen Z., Cui H., Hales K., Qi K., Wooley K. L.: Toroidal triblock copolymer assemblies. Science, 306, 94-97 (2004). https://doi.org/10.1126/science.1102866

[20] Discher D. E., Eisenberg A.: Polymer vesicles. Science, 297, 967-973 (2002). https://doi.org/10.1126/science.1074972

[21] Christian D. A., Tian A. W., Ellenbroek W. G., Levental I., Rajagopal K., Janmey P. A., Liu A. J., Baumgart T., Discher D. E.: Spotted vesicles, striped micelles and Janus assemblies induced by ligand binding. Nature Materials, 8, 843-849 (2009).

https://oi.org/10.1038/nmat2512

[22] Massignani M., LoPresti C., Blanazs A., Madsen J., Armes S. P., Lewis A. L., Battaglia G.: Controlling cellular uptake by surface chemistry, size, and surface topology at the nanoscale. Small, 5, 2424-2432 (2009). https://doi.org/10.1002/smll.200900578

[23] Howse J. R., Jones R. A. L., Battaglia G., Ducker R. E., Leggett G. J., Ryan A. J.: Templated formation of giant polymer vesicles with controlled size distributions. Nature Materials, 8, 507-511 (2009).

https://doi.org/10.1038/nmat2446

[24] Discher B. M., Won Y-Y., Ege D. S., Lee J. C-M., Bates F. S., Discher D. E., Hammer D. A.: Polymersomes: Tough vesicles made from diblock copolymers. Science, 284, 1143-1146 (1999).

https://doi.org/10.1126/science.284.5417.1143

[25] Blanazs A., Armes S. P., Ryan A. J.: Self-assembled block copolymer aggregates: From micelles to vesicles and their biological applications. Macromolecular Rapid Communications, 30, 267-277 (2009).

https://doi.org/10.1002/marc.200800713

[26] Du J., Tang Y., Lewis A. L., Armes S. P.: pH-sensitive vesicles based on a biocompatible Zwitterionic diblock copolymer. Journal of the American Chemical Society, 127, 17982-17983 (2005).

https://doi.org/10.1021/ja0565141

[27] Blanazs A., Massignani M., Battaglia G., Armes S. P., Ryan A. J.: Tailoring macromolecular expression at polymersome surfaces. Advanced Functional Materials, 19, 2906-2914 (2009). https://doi.org/10.1002/adfm.200900201

[28] Napoli A., Valentini M., Tirelli N., Müller M., Hubbell J. A.: Oxidation-responsive polymeric vesicles. Nature Materials, 3, 183-189 (2004).

https://doi.org/10.1038/nmat1081
[29] Qin S., Geng Y., Discher D. E., Yang S.: Temperaturecontrolled assembly and release from polymer vesicles of poly(ethylene oxide)-block-poly( $\mathrm{N}$-isopropylacrylamide). Advanced Materials, 18, 2905-2909 (2006). https://doi.org/10.1002/adma.200601019

[30] LoPresti C., Lomas H., Massignani M., Smart T., Battaglia G.: Polymersomes: Nature inspired nanometer sized compartments. Journal of Materials Chemistry, 19, 3576-3590 (2009). https://doi.org/10.1039/B818869F

[31] Zhang L., Eisenberg A.: Multiple morphologies and characteristics of 'crew-cut' micelle-like aggregates of polystyrene- $b$-poly(acrylic acid) diblock copolymers in aqueous solutions. Journal of the American Chemical Society, 118, 3168-3181 (1996). https://doi.org/10.1021/ja953709s

[32] Zhang L., Eisenberg A.: Formation of crew-cut aggregates of various morphologies from amphiphilic block copolymers in solution. Polymers for Advanced Technologies, 9, 677-699 (1998).

https://doi.org/10.1002/(SICI)10991581(1998100)9:10/11<677::AID-PAT845>3.0.CO;2-\#

[33] Cameron N. S., Corbierre M. K., Eisenberg A.: Asymmetric amphiphilic block copolymers in solution: A morphological wonderland. Canadian Journal of Chemistry, 77, 1311-1326 (1999). https://doi.org/10.1139/v99-141

[34] Antonietti M., Förster S.: Vesicles and liposomes: A self-assembly principle beyond lipids. Advanced Materials, 15, 1323-1333 (2003). https://doi.org/10.1002/adma.200300010

[35] Chen S., Wang Z. L., Ballato J., Foulger S. H., Carroll D. L.: Monopod, bipod, tripod, and tetrapod gold nanocrystals. Journal of the American Chemical Society, 125, 16186-16187 (2003). https://doi.org/10.1021/ja038927x

[36] Glotzer S. C., Solomon M. J.: Anisotropy of building blocks and their assembly into complex structures. Nature Materials, 6, 557-562 (2007). https://doi.org/10.1038/nmat1949

[37] Peng X., Manna L., Yang W., Wickham J., Scher E., Kadavanich A., Alivisatos A. P.: Shape control of CdSe nanocrystals. Nature, 404, 59-61 (2000). https://doi.org/10.1038/35003535

[38] Sun Y., Xia Y.: Shape-controlled synthesis of gold and silver nanoparticles. Science, 298, 2176-2179 (2002). https://doi.org/10.1126/science.1077229

[39] Johnson P. M., van Kats C. M., van Blaaderen A.: Synthesis of colloidal silica dumbbells. Langmuir, 21, 11510-11517 (2005). https://doi.org/10.1021/la0518750

[40] Hayward R. C., Pochan D. J.: Tailored assemblies of block copolymers in solution: It is all about the process. Macromolecules, 43, 3577-3584 (2010). https://doi.org/10.1021/ma9026806 
[41] Gaitzsch J., Messager L., Morecroft E., Meier W.: Vesicles in multiple shapes: Fine-tuning polymersomes' shape and stability by setting membrane hydrophobicity. Polymers, 9, 483/1-483/9 (2017).

https://doi.org/10.3390/polym9100483

[42] Zhang L., Eisenberg A.: Thermodynamic vs kinetic aspects in the formation and morphological transitions of crew-cut aggregates produced by self-assembly of polystyrene- $b$-poly(acrylic acid) block copolymers in dilute solution. Macromolecules, 32, 2239-2249 (1999).

https://doi.org/10.1021/ma981039f

[43] Blanazs A., Madsen J., Battaglia G., Ryan A. J., Armes S. P.: Mechanistic insights for block copolymer morphologies: How do worms form vesicles? Journal of the American Chemical Society, 133, 16581-16587 (2011). https://doi.org/10.1021/ja206301a

[44] Salva R., le Meins J-F., Sandre O., Brûlet A., Schmutz M., Guenoun P., Lecommandoux S.: Polymersome shape transformation at the nanoscale. ACS Nano, 7, 9298 9311 (2013).

https://doi.org/10.1021/nn4039589

[45] Wauters A. C., Pijpers I. A. B., Mason A. F., Williams D. S., Tel J., Abdelmohsen L. K. E. A., Van Hest J. C. M.: Development of morphologically discrete PEGPDLLA nanotubes for precision nanomedicine. Biomacromolecules, 20, 177-183 (2019).

https://doi.org/10.1021/acs.biomac.8b01245

[46] le Fer G., Portes D., Goudounet G., Guigner J-M., Garanger E., Lecommandoux S.: Design and self-assembly of PBLG- $b$-ELP hybrid diblock copolymers based on synthetic and elastin-like polypeptides. Organic and Biomolecular Chemistry, 15, 10095-10104 (2017).

https://doi.org/10.1039/C7OB01945A

[47] Choucair A., Eisenberg A.: Control of amphiphilic block copolymer morphologies using solution conditions. The European Physical Journal E, 10, 37-44 (2003). https://doi.org/10.1140/epje/e2003-00002-5

[48] Discher D. E., Ahmed F.: Polymersomes. Annual Review of Biomedical Engineering, 8, 323-341 (2006). https://doi.org/10.1146/annurev.bioeng.8.061505.095838

[49] Oz U. C., Kucukturkmen B., Ozkose U. U., Gulyuz S., Bolat Z. B., Telci D., Sahin F., Yilmaz O., Bozkir A.: Design of colloidally stable and non-toxic PEtOx-based polymersomes for cargo molecule encapsulation. ChemNanoMat, 5, 766-775 (2019).

https://doi.org/10.1002/cnma.201800606

[50] Hochleitner G., Hümmer J. F., Luxenhofer R., Groll J.: High definition fibrous poly(2-ethyl-2-oxazoline) scaffolds through melt electrospinning writing. Polymer, 55, 5017-5023 (2014).

https://doi.org/10.1016/j.polymer.2014.08.024
[51] Wang X., Li X., Li Y., Zhou Y., Fan C., Li W., Ma S., Fan Y., Huang Y., Li N., Liu Y.: Synthesis, characterization and biocompatibility of poly(2-ethyl-2-oxazoline)-poly(D,L-lactide)-poly(2-ethyl-2-oxazoline) hydrogels. Acta Biomaterialia, 7, 4149-4159 (2011). https://doi.org/10.1016/j.actbio.2011.07.011

[52] Mero A., Pasut V., Via L. D., Fijten M. W. M., Schubert U. S., Hoogenboom R., Veronese F. M.: Synthesis and characterization of poly(2-ethyl 2-oxazoline)-conjugates with proteins and drugs: Suitable alternatives to PEG-conjugates? Journal of Controlled Release, 125, 87-95 (2008).

https://doi.org/10.1016/j.jconrel.2007.10.010

[53] Kara A., Ozturk N., Esendagli G., Ozkose U. U., Gulyuz S., Yilmaz O., Telci D., Bozkir A., Vural I.: Development of novel self-assembled polymeric micelles from partially hydrolysed poly(2-ethyl-2-oxazoline)$c o$-PEI- $b$-PCL block copolymer as non-viral vectors for plasmid DNA in vitro transfection. Artificial Cells, Nanomedicine, and Biotechnology, 46, 264-273 (2018). https://doi.org/10.1080/21691401.2018.1491478

[54] Woodle M. C., Engbers C. M., Zalipsky S.: New amphipatic polymer-lipid conjugates forming long-circulating reticuloendothelial system-evading liposomes. Bioconjugate Chemistry, 5, 493-496 (1994).

https://doi.org/10.1021/bc00030a001

[55] Bauer M., Lautenschlaeger C., Kempe K., Tauhardt L., Schubert U. S., Fischer D.: Poly(2-ethyl-2-oxazoline) as alternative for the stealth polymer poly(ethylene glycol): Comparison of in vitro cytotoxicity and hemocompatibility. Macromolecular Bioscience, 12, 986-998 (2012).

https://doi.org/10.1002/mabi.201200017

[56] Ozkose U. U., Altinkok C., Yilmaz O., Alpturk O., Tasdelen M. A.: In-situ preparation of poly(2-ethyl-2-oxazoline)/clay nanocomposites via living cationic ringopening polymerization. European Polymer Journal, 88, 586-593 (2017). https://doi.org/10.1016/j.eurpolymj.2016.07.004

[57] Kita-Tokarczyk K., Grumelard J., Haefele T., Meier W.: Block copolymer vesicles - using concepts from polymer chemistry to mimic biomembranes. Polymer, 46, 3540-3563 (2005). https://doi.org/10.1016/j.polymer.2005.02.083

[58] Öz U. C., Bozkir A.: Polymeric vesicles and biological applications (in Türkish). Turkish Bulletin of Hygiene and Experimental Biology, 75, 443-458 (2018). https://doi.org/10.5505/TurkHijyen.2018.87369

[59] LoPresti C., Massignani M., Fernyhough C., Blanazs A., Ryan A. J., Madsen J., Warren N. J., Armes S. P., Lewis A. L., Chirasatitsin S., Engler A. J., Battaglia G.: Controlling polymersome surface topology at the nanoscale by membrane confined polymer/polymer phase separation. ACS Nano, 5, 1775-1784 (2011). https://doi.org/10.1021/nn102455z 
[60] Gulyuz S., Ozkose U. U., Kocak P., Telci D., Yilmaz O., Tasdelen M. A.: In-vitro cytotoxic activities of poly(2ethyl-2-oxazoline)-based amphiphilic block copolymers prepared by CuAAC click chemistry. Express Polymer Letters, 12, 146-158 (2018).

https://doi.org/10.3144/expresspolymlett.2018.13

[61] Champion J. A., Mitragotri S.: Role of target geometry in phagocytosis. PNAS, 103, 4930-4934 (2006). https://doi.org/10.1073/pnas.0600997103

[62] Zou T., Dembele F., Beugnet A., Sengmanivong L., Trepout S., Marco S., de Marco A., Li M-H.: Nanobodyfunctionalized PEG- $b$-PCL polymersomes and their targeting study. Journal of Biotechnology, 214, 147-155 (2015).

https://doi.org/10.1016/j.jbiotec.2015.09.034

[63] Lee J. S., Feijen J.: Biodegradable polymersomes as carriers and release systems for paclitaxel using Oregon Green $^{\circledR} 488$ labeled paclitaxel as a model compound. Journal of Controlled Release, 158, 312-318 (2012). https://doi.org/10.1016/j.jconrel.2011.10.025

[64] Li S., Byrne B., Welsh J., Palmer A. F.: Self-assembled poly(butadiene)- $b$-poly(ethylene oxide) polymersomes as paclitaxel carriers. Biotechnology Progress, 23, 278 285 (2007).

https://doi.org/10.1021/bp060208

[65] Upadhyay K. K., le Meins J-F., Misra A., Voisin P., Bouchaud V., Ibarboure E., Schatz C., Lecommandoux S.: Biomimetic doxorubicin loaded polymersomes from hyaluronan-block-poly( $\gamma$-benzyl glutamate) copolymers. Biomacromolecules, 10, 2802-2808 (2009). https://doi.org/10.1021/bm9006419

[66] Caon T., Porto L. C., Granada A., Tagliari M. P., Silva M. A. S., Simões C. M. O., Borsali R., Soldi V.: Chitosan-decorated polystyrene- $b$-poly(acrylic acid) polymersomes as novel carriers for topical delivery of finasteride. European Journal of Pharmaceutical Sciences, 52, 165-172 (2014).

https://doi.org/10.1016/j.ejps.2013.11.008
[67] Simón-Gracia L., Hunt H., Scodeller P., Gaitzsch J., Kotamraju V. R., Sugahara K. N., Tammik O., Ruoslahti E., Battaglia G., Teesalu T.: iRGD peptide conjugation potentiates intraperitoneal tumor delivery of paclitaxel with polymersomes. Biomaterials, 104, 247-257 (2016). https://doi.org/10.1016/j.biomaterials.2016.07.023

[68] Lava K., Verbraeken B., Hoogenboom R.: Poly(2-oxazoline)s and click chemistry: A versatile toolbox toward multi-functional polymers. European Polymer Journal, 65, 98-111 (2015). https://doi.org/10.1016/j.eurpolymj.2015.01.014

[69] Luxenhofer R., Jordan R.: Click chemistry with poly(2oxazoline)s. Macromolecules, 39, 3509-3516 (2006). https://doi.org/10.1021/ma052515m

[70] Ozkose U. U., Yilmaz O., Alpturk O.: Synthesis of poly(2-ethyl-2-oxazoline)- $b$-poly( $\varepsilon$-caprolactone) conjugates by a new modular strategy. Polymer Bulletin, in press (2020).

https://doi.org/10.1007/s00289-019-03038-w

[71] Won Y-Y., Brannan A. K., Davis H. T., Bates F. S.: Cryogenic transmission electron microscopy (cryoTEM) of micelles and vesicles formed in water by poly(ethylene oxide)-based block copolymers. The Journal of Physical Chemistry B, 106, 3354-3364 (2002).

https://doi.org/10.1021/jp013639d

[72] Darling S. B.: Directing the self-assembly of block copolymers. Progress in Polymer Science, 32, 11521204 (2007).

https://doi.org/10.1016/j.progpolymsci.2007.05.004

[73] Tanaka R., Watanabe K., Yamamoto T., Tajima K., Isono T., Satoh T.: A facile strategy for manipulating micellar size and morphology through intramolecular cross-linking of amphiphilic block copolymers. Polymer Chemistry, 8, 3647-3656 (2017). https://doi.org/10.1039/C7PY00646B

[74] Battaglia G., Ryan A. J.: The evolution of vesicles from bulk lamellar gels. Nature Materials, 4, 869-876 (2005).

https://doi.org/10.1038/nmat1501 